\title{
Assessing the potential contribution of excess heat from biogas plants towards decarbonising residential heating
}

Weinand, Jann Michael; McKenna, Russell; Karner, Katharina; Braun, Lorenz; Herbes, Carsten

Published in:

Journal of Cleaner Production

Link to article, DOI:

10.1016/j.jclepro.2019.117756

Publication date:

2019

Document Version

Peer reviewed version

Link back to DTU Orbit

Citation (APA):

Weinand, J. M., McKenna, R., Karner, K., Braun, L., \& Herbes, C. (2019). Assessing the potential contribution of excess heat from biogas plants towards decarbonising residential heating. Journal of Cleaner Production, 238, [117756]. https://doi.org/10.1016/j.jclepro.2019.117756

\section{General rights}

Copyright and moral rights for the publications made accessible in the public portal are retained by the authors and/or other copyright owners and it is a condition of accessing publications that users recognise and abide by the legal requirements associated with these rights.

- Users may download and print one copy of any publication from the public portal for the purpose of private study or research.

- You may not further distribute the material or use it for any profit-making activity or commercial gain

- You may freely distribute the URL identifying the publication in the public portal 


\section{Journal Pre-proof}

Assessing the potential contribution of excess heat from biogas plants towards decarbonising residential heating

Jann Weinand, Russell McKenna, Katharina Karner, Lorenz Braun, Carsten Herbes

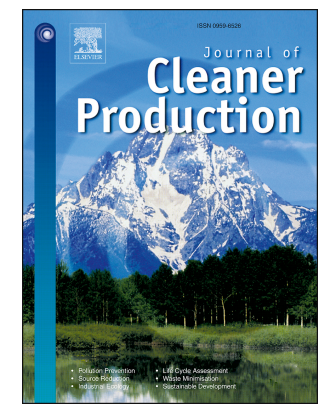

PII:

S0959-6526(19)32616-2

DOI:

https://doi.org/10.1016/j.jclepro.2019.117756

Reference: JCLP 117756

To appear in: Journal of Cleaner Production

Received Date: 8 March 2018

Revised Date: 18 May 2019

Accepted Date: 22 July 2019

Please cite this article as: Weinand J, McKenna R, Karner K, Braun L, Herbes C, Assessing the potential contribution of excess heat from biogas plants towards decarbonising residential heating, Journal of Cleaner Production (2019), doi: https://doi.org/10.1016/j.jclepro.2019.117756.

This is a PDF file of an article that has undergone enhancements after acceptance, such as the addition of a cover page and metadata, and formatting for readability, but it is not yet the definitive version of record. This version will undergo additional copyediting, typesetting and review before it is published in its final form, but we are providing this version to give early visibility of the article. Please note that, during the production process, errors may be discovered which could affect the content, and all legal disclaimers that apply to the journal pertain.

(C) 2019 Published by Elsevier Ltd. 


\title{
Assessing the potential contribution of excess heat from biogas plants towards decarbonising residential heating
}

\author{
Jann Weinand ${ }^{1}$, Russell McKenna ${ }^{1,2, *}$, Katharina Karner $^{3}$, Lorenz Braun ${ }^{4}$, Carsten Herbes $^{5}$ \\ ${ }^{1}$ Chair of Energy Economics, Karlsruhe Institute for Technology, Germany \\ 2 DTU Management Engineering, Technical University of Denmark, Denmark \\ ${ }^{3}$ Institute of energy, transport and environmental management, FH Joanneum, Austria \\ ${ }^{4}$ Nuertingen-Geislingen University, Faculty of Agriculture, Economics and Management, Germany \\ ${ }^{5}$ Nuertingen-Geislingen University, ISR, Nuertingen, Germany
}

\begin{abstract}
${ }^{*}$ Corresponding author: current address: DTU Management Engineering, Produktionstorvet, Building 426, Room 130A, 2800 Kgs. Lyngby, Denmark, Tel. +45 467751 59, Email: rkenna@dtu.dk
\end{abstract}

\begin{abstract}
This paper analyses the technical potential for utilising excess heat from biogas plants, in order to supply local settlements through district heating. Based on a survey of around 600 biogas plant operators, the fractions of excess heat from the cogeneration units in these plants are analysed. A heuristic is developed to match biogas plants (heat sources) with local settlements (heat sinks) in order to determine a least-cost district heating supply for residential buildings. Two criteria are employed, namely the $\mathrm{CO}_{2}$ abatement costs and the payback period, which represent the macro- and microeconomic perspectives respectively. Based on the survey, the mean fraction of excess heat is $40 \%$, which is in agreement with other empirical studies. Extrapolating this fraction to the German biogas plant stock, which is selected as case study, leads to technically feasible $\mathrm{CO}_{2}$ savings of around $2.5 \mathrm{MtCO}_{2} / \mathrm{a}$. Employing the criteria of $\mathrm{CO}_{2}$ abatement costs and payback period yields about $2 \mathrm{MtCO}_{2} / \mathrm{a}$ below $\mathrm{CO}_{2}$ abatement costs of $200 € / \mathrm{tCO}_{2}$ and below a payback period of 9 years. This represents about $0.25 \%$ of the total German $\mathrm{CO}_{2}$ emissions in 2016 or around $2.5 \%$ of all $\mathrm{CO}_{2}$ in residential buildings. Alternative threshold values of $80 € / \mathrm{tCO} 2$ and 5 years payback period reduce the carbon reduction potential to about $0.5 \mathrm{MtCO}_{2}$ and $0.75 \mathrm{MtCO}_{2}$ respectively. These relatively high average costs are related to the typically low population density in rural regions where biogas plants are located. These potentials are concentrated in around 3,500 of 11,400 municipalities, where district heating from biogas plants could reduce $\mathrm{CO}_{2}$ emissions per capita by an average of $250 \mathrm{kgCO}_{2} / \mathrm{a}$ and cover $12 \%$ of the total heating demand. Apart from a methodology that can be transferred to any country with comparable data availability, the present study demonstrates that the use of excess heat in biogas plants can contribute to global decarbonisation.
\end{abstract}

\section{Highlights}

- Biogas plants often have unutilised excess heat

- A survey of 600 German plants reveals a mean excess heat fraction of $40 \%$

- Novel heuristic connects plants to settlements through district heating

- Criteria employed: $\mathrm{CO}_{2}$ abatement costs and payback period

- The technically feasible $\mathrm{CO}_{2}$ abatement is around $2 \mathrm{MtCO}_{2}$

Keywords: biogas plant, excess heat, energy autonomy, $\mathrm{CO}_{2}$ abatement costs, district heating 


\section{Nomenclature}

Variable /

Description

Unit

Parameter

$a f$

Annuity factor

$a_{111}$

Area size of a settlement area with continuous urban fabric

$\mathrm{m}^{2}$

$a_{112}$

Area size of a settlement area with discontinuous urban fabric

$\mathrm{m}^{2}$

$A_{B C}$

Share of brown coal in heat supply for settlement area

$\%$

Share of electricity in heat supply for settlement area

$\%$

$A_{E L}$

Share of gas in heat supply for settlement area

$\%$

$A_{\text {Gas }}$

Share of hard coal in heat supply for settlement area

$\%$

$A_{H C}$

Share of heating oil in heat supply for settlement area

$\%$

$A_{\text {oil }}$

Total building space of a settlement area

$\mathrm{m}^{2}$

CO2 $2_{\text {costs }}$

$\mathrm{CO}_{2}$ abatement costs

$€ / \mathrm{tCO}_{2}$

$\mathrm{CO}_{\text {saved,SA }}$

Saved $\mathrm{CO}_{2}$ emissions in a settlement area

$\mathrm{tCO}_{2}$

C1

Construction cost parameter per length unit for district heating network

$€ / \mathrm{m}$

$C 2$

Construction cost parameter per area unit for district heating network

$€ / \mathrm{m}^{2}$

$C R$

Coverage ratio of the heat supply

$\%$

$d f$

Discount factor

$\%$

$d_{S A}$

Average diameter of the district heating pipelines

$\mathrm{m}$

$D I S_{S A}$

Distance between a biogas plant and a settlement area

$\mathrm{m}$

Plot ratio, used to categorize typical city districts

$E F_{B C}$

$\mathrm{CO}_{2}$ emission factor of brown coal

$\mathrm{kgCO}_{2} / \mathrm{kWh}$

$E F_{E L}$

$\mathrm{CO}_{2}$ emission factor of electricity

$\mathrm{kgCO}_{2} / \mathrm{kWh}$

$E F_{\text {Gas }}$

$\mathrm{CO}_{2}$ emission factor of gas

$\mathrm{kgCO}_{2} / \mathrm{kWh}$

$E F_{H C}$

$\mathrm{CO}_{2}$ emission factor of hard coal

$\mathrm{kgCO}_{2} / \mathrm{kWh}$

EF $F_{\text {oil }}$

$\mathrm{CO}_{2}$ emission factor of oil

$\mathrm{kgCO}_{2} / \mathrm{kWh}$

$E H_{B G P}$

Share of available excess heat in a biogas plant

$\%$

Share of already used excess heat in a biogas plant

$\%$

Sum of expenses for the supply of a settlement with district heating

$€$

Number of residential buildings in a federal state / municipality with one apartment

$F_{1}$

Number of residential buildings in a federal state / municipality with two apartments

$F_{2}$

Number of residential buildings in a federal state / municipality with three or more apartments

$F_{3}$

Mean living space per apartment in a federal state

$\mathrm{m}^{2}$

Mean living space per apartment in a municipality

$\mathrm{m}^{2}$

$F_{\text {mean,m }}$

Total living space in a federal state

$\mathrm{m}^{2}$

$F_{\text {total }}$

Mean specific heat demand in a settlement area

$\mathrm{kWh} / \mathrm{m}^{2}$ 
$H D_{S A} \quad$ Total heat demand in a settlement area, reduced by the share of heat generation technologies that should not be replaced by the excess heat

$H D_{S A_{\text {total }}}$

Total heat demand in a settlement area

$\mathrm{kWh}$

$H D C_{S A}$

Specific heat distribution costs of the excess heat

$€ / G J$

$I_{\text {con,SA }}$

Investment in the pipeline for connecting the biogas plant and the settlement area

Excess heat profile of a biogas plant

$L P_{S A}$

Heat demand load profile of a settlement area

$L S_{1}$

Living space in a settlement area

$\mathrm{m}^{2}$

$L S_{2} \quad$ Adjusted living space in a settlement area, if $L S_{\text {total1 }}$ is not equal to $L S_{\text {total2 }}$

Total number of buildings in a square kilometre of the census data grid

Number of buildings in a settlement area with continuous urban fabric

Number of buildings in a settlement area with discontinuous urban fabric

Net present value for the supply of a settlement with district heating 


\section{Introduction}

The expansion of renewable energy technologies (RETs) is largely being driven by private individuals, farmers and energy cooperatives in the context of community energy (Klaus Novy Institut e.V. \& trend:research 2011, trend:research 2017). This trend involves these actors investing in and/or operating RETs, including wind, solar and bioenergy plants, in some cases also buying the local energy infrastructure (gas, electricity, heating networks) back from the local utility. They are mainly motivated by a desire to 'take control' of their local energy supply (system) and thus become more independent from centralised markets and energy suppliers (for reviews, cf. Müller et al. 2011, Rae \& Bradley 2012). Many community energy projects declare an objective of energy autonomy, with some examples in Germany including the $100 \%$ Renewable Energy Regions and the Bioenergy Villages. Despite possibly having potentially negative system wide impacts (McKenna 2018), municipalities typically define autonomy on an annual basis and for electricity alone ${ }^{1}$. The costs of these RETs were historically higher than those of conventional technologies, meaning they relied on subsidies to be economic. However, recent rapid reductions in costs for photovoltaics and batteries have provided a renewed incentive for attempts to become energy autonomous at a local scale (Nykvist \& Nilsson 2015).

Many studies have techno-economically analysed the scope to achieve a local energy supply from renewable sources (e.g. Jenssen et al. 2010, Schmidt et al. 2012 and Burgess et al. 2012). Most conclude that a completely autonomous energy supply is only feasible in rural municipalities with large bioenergy resources, and even then, large storage capacities are required which lead to high costs. In the context of decentralised energy supply, a related stream of research is concerned with (industrial) excess heat and the possibilities of utilising this as an energy input, e.g. for space heating. Several studies in this area have analysed the technical and/or economic potential of excess heat from industry, often based on emissions data from individual industrial plants. Noteworthy are the studies McKenna \& Norman (2010), Fang et al. (2013, 2015), Brückner et al. (2014), Miró et al. (2015, 2016), Bühler et al. (2017), and the ongoing Heat Roadmap Europe project (Persson et al. 2014).

One additional source of excess heat potential are biogas plants, which valorise organic matter into biogas through fermentation (cf. section A.1 in the appendix). This biogas is typically combusted in a cogeneration unit, whereby the electricity is generally fed into the grid. Within Europe, Germany accounts for around 50\% (329 PJ in 2015) of the total biogas production (Scarlat et al. 2018). A legal requirement was introduced in Germany with the Renewable Energy Sources Act (EEG) 2012, that new biogas plants must utilise at least $25 \%$ of their excess heat in the first year of operation and $60 \%$ thereafter (Mergner et al. 2013). Despite this, there are many operating plants, some of which were commissioned before this time, with much lower levels of heat utilisation. Section A.1 in the appendix gives an overview of the current status of the German biogas industry.

Against this background of decentralised energy systems, aspirations for local energy autonomy and excess heat potentials, this study analyses the technical and economic potential for recovering excess heat from biogas plants in Germany to supply local buildings

\footnotetext{
${ }^{1}$ At the time of writing only one municipality is known to the authors that is aiming to be completely energy autonomous, namely Bordelum, cf. http://www.sonnenseite.com/de/energie/norddeutsche-gemeinde-stelltkomplett-auf-erneuerbare-energien-um.html.
} 
with low-carbon space heating. Germany is selected as the case study due to the high biogas production mentioned above. The objective is to determine the amount of heat that could technically be recovered as well as its associated costs, in order to give indications of promising locations. The paper addresses the following research questions:

- How does the excess heat from biogas plants match the existing heat sinks?

- What contribution can the use of biogas excess heat make to the energy autonomy of municipalities?

- In which locations is the utilisation of biogas excess heat economically interesting for investors?

The employed methodology involves input from a survey of around 600 biogas plant operators for a GIS-based analysis of heat sources and sinks. Thereby, a developed heuristic matches and connects the heat sources and sinks with district heating pipelines based upon a least-cost approach. The results are therefore of relevance to local decision makers, biogas plant operators and researchers in the field of energy system analysis. In particular the quantitative results offer an indication of the costs and related $\mathrm{CO}_{2}$ saving potentials on a local level, in order to underpin local decision-making.

The remainder of the paper is structured as follows. The following section 2 gives an overview of relevant literature on the subject of designing district heating networks (DHNs). The subsequent section 3 outlines the employed methodology, including the plant operator survey, the approach to spatially locating the analysed plants, the determination of the residential building heat demand at a local level and the heuristic to match heat sources and sinks. Then section 4 presents and discusses the results, first for the survey sample and then for a tentative scale-up for the whole of Germany. The paper closes in section 5 with conclusions and an outlook.

\section{Literature review}

In the following literature review, Table 1 provides a summary of the methodology and problem sizes used in the evaluated studies. The distinction between bottom-up and topdown studies is made in such a way that bottom-up studies, for example, are based on individual buildings and roads, while the top-down approach uses heat and population densities to calculate potentials. District heating $(\mathrm{DH})$ pipelines with length-dependent costs are required to utilise the excess heat of biogas plants in residential settlements. In section 2.1, studies on small-scale DHNs will be discussed before section 2.2 focuses on large-scale DHNs. 
Table 1: Studies about designing and dimensioning DHNs ( $R=$ residential sector, $C=$ commercial sector, $I=$ industrial sector).

\begin{tabular}{|c|c|c|c|c|c|c|c|}
\hline Study & Methodology & $\begin{array}{l}\text { Bottom-up or } \\
\text { top-down } \\
\text { methodology }\end{array}$ & $\begin{array}{l}\text { Network } \\
\text { building or } \\
\text { expansion }\end{array}$ & Sector & Region & $\begin{array}{l}\text { Number of } \\
\text { customers / } \\
\text { nodes / sinks }\end{array}$ & $\begin{array}{l}\text { Number of } \\
\text { suppliers } \\
\text { sources }\end{array}$ \\
\hline Chinese 2008 & Optimisation model & Bottom-up & Building & $\mathrm{R}, \mathrm{C}, \mathrm{I}$ & Urban area (Italy) & 11 & 1 \\
\hline Casisi et al. 2009 & Optimisation model & Bottom-up & Building & $\mathrm{C}$ & Urban area (Italy) & 6 & 9 \\
\hline Dobersek \& Goricanec 2009 & Optimisation model & Bottom-up & Building & n.a. & Urban area & 23 & 1 \\
\hline Fazlollahi et al. 2014 & Cluster analysis and optimisation model & Top-down & Building & n.a. & Urban area & 13 & n.a. \\
\hline Nielsen 2014 & Heuristic & Bottom-up & Expansion & n.a. & $\begin{array}{l}\text { Arbitrary Danish } \\
\text { municipality }\end{array}$ & n.a. & n.a. \\
\hline $\begin{array}{l}\text { Karschin \& } \text { Geldermann } \\
2015\end{array}$ & Optimisation model & Bottom-up & Building & $\mathrm{R}$ & Rural area & 71 & 1 \\
\hline Bordin et al. 2016 & Optimisation model & Bottom-up & Expansion & $\mathrm{R}, \mathrm{C}$ & Urban area & 1,000 & 1 \\
\hline $\begin{array}{l}\text { Yılmaz Balaman \& Selim } \\
2016\end{array}$ & Optimisation model & Bottom-up & n.a. & $\mathrm{R}$ & Urban area (Turkey) & 10 & 1 \\
\hline Delangle et al. 2017 & Optimisation model & Bottom-up & Expansion & n.a. & Urban area & 31 & 1 \\
\hline Unternährer et al. 2017 & Cluster analysis and heuristic & Top-down & Building & n.a. & $\begin{array}{ll}\text { Urban } & \text { area } \\
\text { (Switzerland) } & \end{array}$ & 410 & n.a. \\
\hline Coss et al. 2018 & Optimisation model & Top-down & $\begin{array}{l}\text { Just operation } \\
\text { of the } \mathrm{DHN}\end{array}$ & $\mathrm{R}, \mathrm{C}$ & n.a. & n.a. & n.a. \\
\hline Guelpa et al. 2018 & Optimisation model & Bottom-up & Expansion & $\mathrm{R}, \mathrm{C}, \mathrm{I}$ & Urban area (Italy) & 182 & 5 \\
\hline Karner et al. 2018 & Heuristic & Bottom-up & Expansion & $\mathrm{R}, \mathrm{C}, \mathrm{I}$ & $\begin{array}{l}\text { Urban } \quad \text { area } \\
\text { (Austria) }\end{array}$ & n.a. & n.a. \\
\hline Marquant et al. 2018 & Cluster analysis and optimisation model & Bottom-up & Building & $\mathrm{R}, \mathrm{C}$ & $\begin{array}{ll}\text { Urban } & \text { area } \\
\text { (Switzerland) } & \end{array}$ & 32 & n.a. \\
\hline Marty et al. 2018 & Optimisation model & Bottom-up & Building & n.a. & n.a. & 9 & 1 \\
\hline Soltero et al. 2018 & Heuristic & Top-down & $\begin{array}{l}\text { Just cost } \\
\text { calculation }\end{array}$ & $\mathrm{R}$ & Rural areas & 499 & n.a. \\
\hline
\end{tabular}




\subsection{Small-scale district heating networks}

Approaches for the design and dimensioning of small-scale DHNs have already been presented and discussed in numerous studies. In Chinese (2008), DH and cooling systems are designed using a mixed integer optimisation model. Central and decentralised heat production are combined while taking network costs into account. A mixed integer linear program was developed by Casisi et al. (2009) to determine the optimal layout of a DH system and the optimal operating strategy for a distributed cogeneration system while minimising the total cost of ownership and operation. Dobersek \& Goricanec (2009) identify the optimal tree branch path of a DHN in an urban area, under consideration of construction costs, pump and electricity costs. The optimal network for a complete supply of all consumers is determined, whereby the locations of the heat source and consumers are defined in advance. Some specific nodes that do not represent consumers are used for branches of district heating pipelines (DHPs). Delangle et al. (2017) investigate the extension of existing DHNs. Besides $\mathrm{DH}$, gas boilers, biomass boilers, heat pumps and heat storages are included in a mixed integer linear optimization. The model can determine the optimal investment plan for a DHN extension and can be applied to other case studies. In the latter case, the existing DHN and the buildings to be connected must be known. Karschin \& Geldermann (2015) present an optimisation model which determines the location and capacity of a bioenergy plant and the associated DHN. Possible locations are defined beforehand as the locations of the plant. The study serves to support bioenergy villages in planning their energy systems. The fuzzy optimisation model in Yılmaz Balaman \& Selim (2016) designs biomass based renewable energy supply chains and DH systems with heat storages in specific regions. Another study on small scale DHNs is that of Coss et al. (2018). In their article, a multiobjective optimisation model is presented, which determines the energy supply of a biomass plant for $\mathrm{DH}$ purposes. However, the model does not optimise the design but only the operation mode of the DHN. Marty et al. (2018) highlight the relevance of a simultaneous optimisation of a DHN and an organic rankine cycle as parts of a geothermal plant. The location of the $\mathrm{DH}$ plant is specified in advance for the optimisation model, and one consumer is already connected to the DHN. In the case of the utilisation of excess heat from biogas as in our study, the connection of a customer in advance is not meaningful, since the use of excess heat is not always worthwhile. Karner et al. (2018) investigate heat flexibilities in cities through excess heat from industry. One of the presented options is the use of the heat in DHNs. Nielsen (2014) develops an algorithm for the economic evaluation of possible network expansions based on existing DHNs. Geographical data are used for cost calculations for heat generation, distribution and transmission. In order to reduce model complexity, Fazlollahi et al. (2014) design the DHN on the basis of cluster analyses. The clustering of urban areas is intended to reduce the model complexity of a subsequent optimisation model by aggregating the energy demand and $\mathrm{DH}$ distribution costs in the resulting urban districts. In the investigated city there are already 13 clusters needed to adequately represent the demand and costs.

In many cases, the studies do not address the applicability of the methods to large-scale problems with many heat suppliers and it can be assumed that the models are not suitable for this purpose (Casisi et al. 2009; Dobersek \& Goricanec 2009; Karschin \& Geldermann 2015; Marty et al. 2018). In addition, the studies show that the investigation of small-scale problems with the applied methods already leads to computational and time restrictions and 
is therefore not suitable for large-scale applications (Chinese 2008; Fazlollahi et al. 2014; YIImaz Balaman \& Selim 2016). Chinese (2008) recommends the use of heuristics instead of optimisation to solve larger problems in a reasonable time. Other studies require extensive data for the application of the models, which are not available for large-scale problems and/or for application in Germany (Nielsen 2014; Karner et al. 2018).

\subsection{Large scale district heating networks}

In the literature are only a few studies which design DHNs for large regions. Soltero et al. (2018) follow a similar approach to our study. The authors develop a methodology to design biomass DH systems in rural areas and examine 499 municipalities in Spain that are not connected to the gas network. In the region under consideration, $\mathrm{DH}$ from biomass can save 5.4 $\mathrm{Mt}_{\mathrm{co} 2}$ per year. The study shows several differences to our paper. Firstly, the heuristic estimates the length of the DHN instead of determining the length by geographical methods. Furthermore, no existing plants are considered, but the potentials of new plants are estimated. In addition, the approach is only applicable to rural areas and the investment decision is made for entire municipalities, while in our analysis it is possible to connect parts of municipalities, i.e. settlements, to the DHN. Marquant et al. (2018) develop a combined clustering schema to overcome time-constraints while estimating the potential for DHNs. In this study, however, only 32 buildings are examined in a case study. These buildings are divided into four clusters to reduce the variables for the subsequent $\mathrm{DH}$ optimisation model. However, the calculation for the whole model takes even in this case more than 250 hours. Unternährer et al. (2017) also use a clustering approach before determining the optimum design of a geothermal DHN for the resulting clusters. The cluster analysis is performed using an optimisation model. On the computer used in the study with 8 cores and $32 \mathrm{~GB}$ RAM, the model could not be executed from a cluster number of 420 clusters or larger due to memory restrictions. The extension of existing DHNs is subject in the study of Bordin et al. (2016). The network can be expanded by potential pipelines and customers in an optimisation model to maximise the net profit. The tree configuration of the network is optimised with one heat supply plant as starting point. However, the model is not suitable for the purposes of our study, as only one network with one heat generation plant can be considered and existing networks are extended. The same applies to the study by Guelpa et al. (2018), in which large DHNs are also expanded with the help of optimisation.

The evaluation of the literature on the design of DHNs shows that a large problem size of the kind described in our article has not yet been investigated in any study. In some methods, even smaller DHNs encounter temporal or computing problems (Unternährer et al. 2017; Marquant et al. 2018). In addition, the methods developed so far are not applicable to the case presented in this paper (Soltero et al. 2018), for example due to the need for extensive building data (Guelpa et al. 2018). Furthermore, no procedure has yet been developed to design many DHNs at the same time. The methodology developed in our study is therefore not only applied to the novel case of utilising excess heat from all German biogas plants, but also represents a further development with regard to dealing with large problems in $\mathrm{DH}$ design. Due to the evaluated literature and the time and calculation restrictions mentioned therein, the method developed in our study is not an optimisation but a heuristic. The developed heuristic differs in the following points from the problem formulations in the above mentioned studies: 
- It is evaluated whether a connection of a settlement is worthwhile and "to which percentage" a settlement should be connected. This can result in a biogas plant not being connected to heat consumers, which means that the excess heat remains unused.

- A very large problem has to be solved (with about 50,000 biogas plants / settlements).

- Subtrees / independent DHNs are allowed (up to 10,000, as there are as many sources / biogas plants).

- Possible pipelines go from any biogas plant / settlement to any other nearby settlement.

Besides Germany, the data used to represent settlement areas are available for 38 other European countries (EEA 2018). The heuristic could be extended to any country with similar available data. As demonstrated in Scarlat et al. (2018), there is also a lot of biogas production in other countries than Germany.

\section{Method and approach}

This study uses different methods in a multi-stage approach. The summarizing representation in Figure 1 is intended to provide a better understanding of the algorithm explained in this section. The left-hand side of Figure 1 shows in which subsection the respective part of the algorithm is explained. Firstly, the results of an extensive survey of biogas plant operators in Germany are taken into account with regard to their heat utilisation rates (cf. section 3.1, Herbes \& Halbherr 2017). Secondly, 10,446 biogas plants as well as the 38,414 CORINE Land Cover (CLC) settlement areas in Germany are examined with regard to their technical and geographical characteristics (cf. section 3.1). Subsequently, the local demand for heat in buildings in all German settlement areas and the excess heat availability of biogas plants are calculated (cf. section 3.3). In order to provide a least cost solution, options to integrate the excess heat from the biogas plants into DHNs are explored. In this context, in particular the distances between the biogas plants and the settlement areas are determined. Based on published methods for $\mathrm{DH}$ systems assessment and dimensioning, the possible $\mathrm{CO}_{2}$ savings and associated costs as well as the payback periods are determined for combinations of biogas plants and their nearest residential areas. By focussing on the connections with the lowest $\mathrm{CO}_{2}$-abatement costs/payback period, the most environmentally and economically attractive locations for a district heat network development are identified (cf. section 3.4).

\subsection{Biogas plant survey}

In the summer of 2016, an online survey of those members of the German Biogas Association that run a biogas plant was conducted, resulting in a gross sample of 2,724 operators2 (Herbes et al. 2018a). After the development of the questionnaire, which was a joint undertaking of Nuertingen-Geislingen University and the German Biogas Association (GBA), extensive cognitive pre-testing with external biogas experts, GBA staff and plant

\footnotetext{
${ }^{2}$ For an overview of the historical development and current status of the German biogas sector, the interested reader is referred to Appendix A.1.
} 
operators was carried out before fielding the survey. To decrease nonresponse bias after the first phase, a telephone campaign in those federal states that were underrepresented in the answers was conducted. These efforts resulted in a final data set of $n=602$ plant operators, which is equivalent to a response rate of $22 \%$ (according to response rate 2 (RR 2), cf. AAPOR (2015)). Regarding the distribution of federal states, the sample shows a small overrepresentation of Bavaria and Baden-Wuerttemberg (cf. Figure 5). Regarding size and commissioning year, the sample is statistically representative of the entire German biogas plant stock. Amongst other things, the data set includes location, plant size, percentage of the already used heat, utilisation paths and various data on prices and price models, which are not relevant for the present study (cf. Section A.2 in the appendix and Herbes \& Halbherr 2017 for more information).

\subsection{Biogas plant register and CORINE Land Use Data}

The plants from the survey can be identified and mapped in the Energymap plant register (Engel 2015) on the basis of their year of commissioning, postcode and nominal power. Further and more detailed information could then be taken from the plant register, such as the full load hours in recent years. The full load hours in this study represent the total operating hours recalculated to full load hour equivalents. The data from the survey were used for heat utilisation (cf. section 4.2).

The Energymap plant register contains the coordinates of the biogas plants with a maximum error of $3 \mathrm{~km}$. Therefore, the locations of the 10,446 plants in Germany could be mapped with the help of the geoinformation system QGIS. The plants from the survey are a subset of these 10,446 plants. CLC data from the European Environment Association (EEA 2016) were used as a source for the settlement areas. The shapefiles of these areas for Germany are provided by the Federal Office of Cartography and Geodesy (Lenk et al. 2017a). Urban areas are distinguished according to the density of the urban fabric, into "continuous urban fabric" (denoted with the number "111") and "discontinuous urban fabric" areas (denoted with the number "112"). The boundary between the 111 and 112 areas is mainly determined by the presence and quantity of vegetation (EEA 1995). Overall, the German settlement areas are divided into 38,414 of these areas. The left part of Figure 2 shows an exemplary section of these areas. 


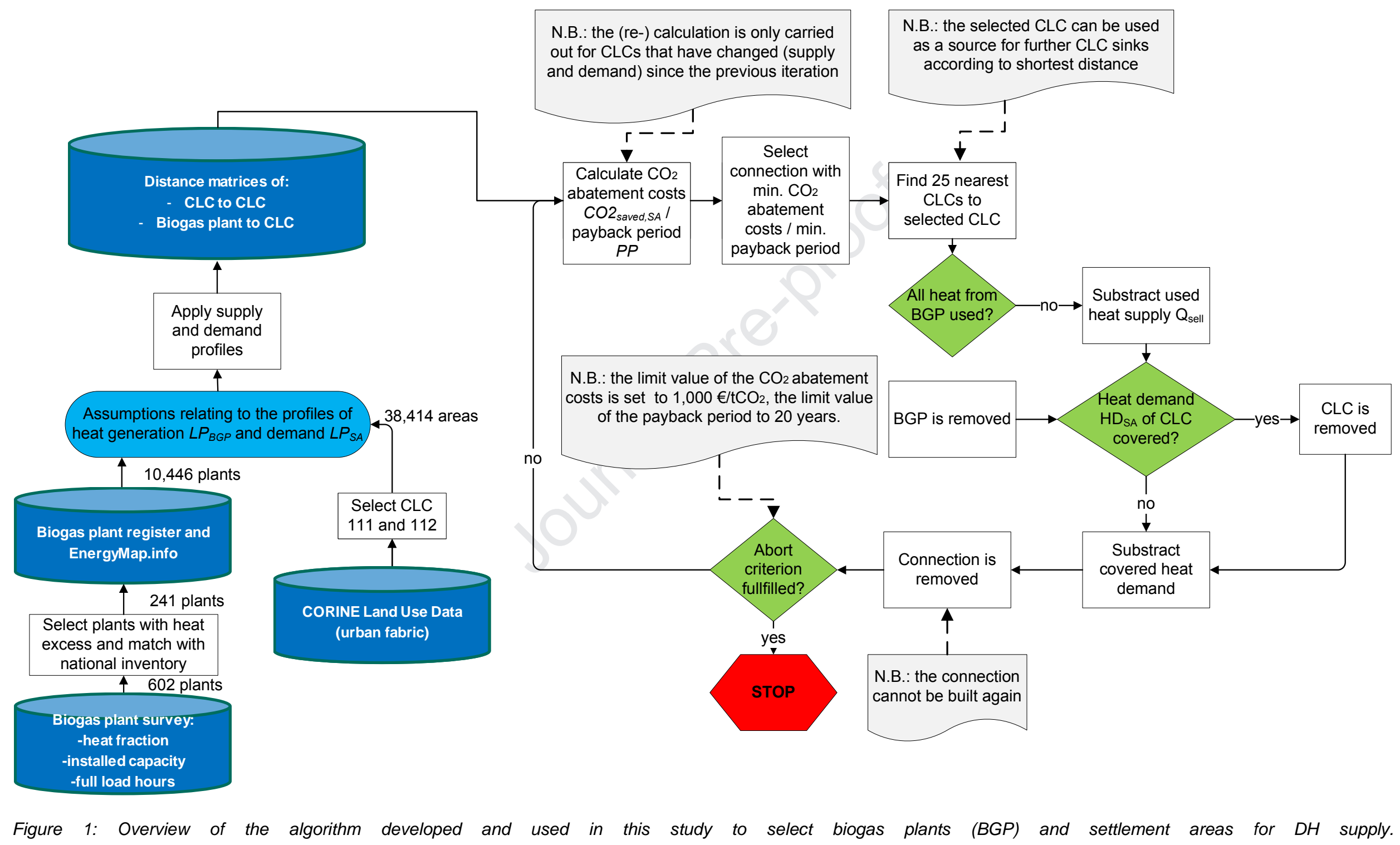




\subsection{Heat demand and generation}

The method for determining the heat demand of the settlement areas and the excess heat availability of the biogas plants is explained in sections 3.3.1 and 3.3.2.

\subsubsection{Heat demand}

Data on the building stock in Germany were taken from the census of the Federal Statistical Office to determine the heat demand in the settlement areas. For more information on determining the census data, see Statistisches Bundesamt (2015b). The census data include data on building age, building type and share of $\mathrm{DH}$, and are assigned with the help of the Lambert-Azimuthal-Equal Area Projection (ETRS89-LAEA) into INSPIRE-compliant 1-km² grid cells (Statistisches Bundesamt 2016b). Therefore, the CLC settlement areas must also be assigned to this grid. For this purpose, the CLC settlement areas were intersected with the ETRS89-LAEA grid. The result can be seen on the right part of Figure 2. The black dots in the CLC areas represent the area centroids. Industrial and commercial areas are excluded from this analysis due to the lack of data for industrial heat demand.
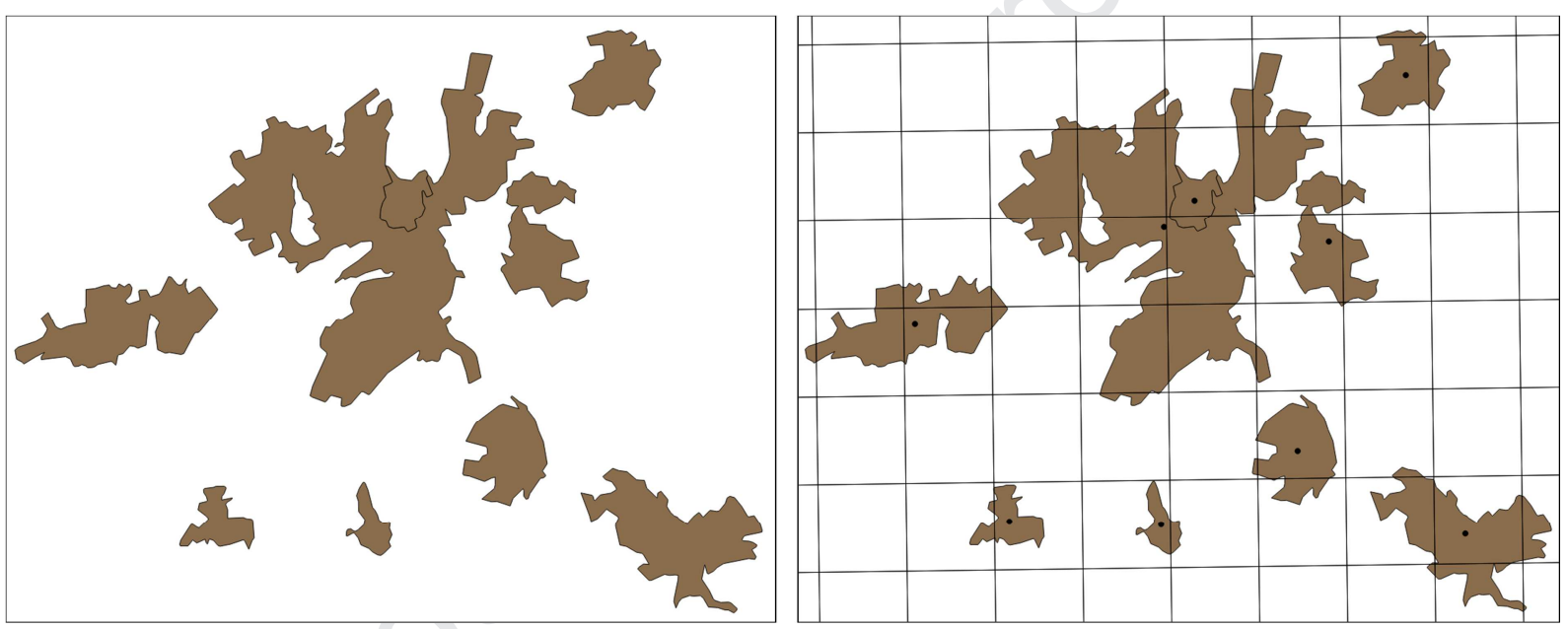

Figure 2: Exemplary section of the "111" and "112" CORINE areas (left part) and the intersection with the ETRS89-LAEA grid (right part).

After the allocation of the CLC sub-areas to the square kilometres, the census data were assigned to the CLC areas. The data per square kilometre must be distributed to all CLC sub-areas in the grid. In addition to taking into account the area share, a distinction is also made between 111 and 112 areas (cf. section 3.1). The 111 areas represent settlement areas of which on average $90 \%$ are covered with buildings. For the 112 areas, the proportion of building area is on average 65\% (EEA 1995). These values are used as building densities. Since the census data is related to buildings, this information can be used to divide the census data into areas. Section A.3 of the appendix shows the calculation of the heat demand $H D_{S A_{\text {total }}}$ in the individual settlements using these census data in detail. In many settlement areas there are buildings whose heat demand is covered by $\mathrm{DH}$ systems. For these settlements, the heat demand $H D_{S A}$ is deducted from the total heat demand $H D_{S A_{\text {total }}}$. Since it is not known which building types have $\mathrm{DH}$ systems, the share of $\mathrm{DH}$ systems $S_{D H}$ in the settlement is deducted from the total heat demand. In addition, the heat demand is reduced by the share of technologies that should not be replaced by $\mathrm{DH}$ with biogas excess heat, such as renewables (cf. Eq. 1). 


$$
H D_{S A}=H D_{S A_{\text {total }}} \cdot\left(1-S_{D H}-S_{W P}-S_{B i o}-S_{S E}-S_{G T}\right) \#(1)
$$

$S_{W P}$ stands for the proportion of heat supplied by wood pellets, $S_{B i o}$ for biomass, $S_{S E}$ for solar energy and $S_{G T}$ for geothermal and other environmental heat. These shares are not to be replaced because the emission factors are lower or not significantly higher than those for $\mathrm{DH}$ from biogas plants (LfU 2016). Apart from the share of DH (municipality level), all shares are based on figures at federal state level (Statistisches Bundesamt 2016a). Eq. 1 is based on the assumption that the heat demand of buildings which already have a building connection for $\mathrm{DH}$ is completely covered by the existing $\mathrm{DH}$. With the census of 2011 as a basis, the share of $\mathrm{DH}$ in settlement areas in Germany ranges from 0 to $95 \%$ (mean value is $2.65 \%{ }^{3}$ ).

In the next step, a heat load profile $L P_{S A}$ is assigned to each settlement area (cf. Eq. 2). For this purpose, a standardised profile of a DHN $S L P_{H D}$ with an hourly resolution is used, which is adapted according to the previously determined heat demand $H D_{S A}$ (for the standardised profile, see Karner et al. (2016)).

$$
L P_{S A}=H D_{S A} \cdot S L P_{H D} \#(2)
$$

\subsubsection{Heat generation}

For each biogas plant, the thermal capacity, the full load hours and the share of already used excess heat $E H_{\text {used }}$ are known, as explained above. If the thermal power $P_{t h}$ is not given, it is determined with the help of the electrical power and a heat-to-power coefficient of 1 (Klein et al. 2014). In case no full load hours are known, these are determined on the basis of the electrical power and the amount of energy generated per year. On the basis of this data, an hourly load profile $S L P_{B G P}$ can now be assigned to each biogas plant. Biogas plants are typically operated as baseload, but recent changes to the energy-political framework (cf. section A.1 in the appendix) have led to more flexible operation. Since the maximum thermal power requirement is in winter, it is assumed that the biogas plant will be primarily operated during these months. On the basis of the full-load hours, the time window of operation during the winter is extended in both directions until the full load hours are reached (cf. Figure 12). Since excess heat is only generated during operation, the period of electricity production also corresponds to the period during which excess heat is generated. The excess heat profile $L P_{B G P}$ is determined according to Eq. 3.

$$
L P_{B G P}=S L P_{B G P} \cdot P_{t h} \cdot\left(1-E H_{\text {used }}\right) \#(3)
$$

\subsubsection{Coverage and supply ratio}

Having assigned load profiles to both the biogas plants and the settlement areas, the coverage ratio $C R$ and the supply ratio $S R$ can be determined. The supply ratio is based on the total amount of available excess heat $E H_{B G P}$ and puts the available excess heat in proportion to the heat demand $H D_{S A}$ of the settlement areas (cf. Eq. 4).

$$
S R=\frac{E H_{B G P}}{H D_{S A}} \#(4)
$$

\footnotetext{
${ }^{3}$ In the calculation of this value, all municipalities are equally weighted. Therefore it must not be confused with the proportion of district heating in the residential heat supply in Germany of $13.8 \%$ (Euroheat \& Power 2017).
} 
By contrast, the coverage ratio is based on an hourly coverage and thus takes into account the time characteristics of supply and demand. As a result, the coverage ratio cannot be greater than the supply ratio. The coverage ratio $C R$ is calculated in Eq. 5 for every hour. If the heat demand $H D_{S A}$ is greater than the excess heat $E H_{B G P}$ in an hour $t$, the share that can be covered by the excess heat is calculated in Eq. 6. If the share of excess heat is greater, the heat demand can be fully covered (cf. Eq. 7). The hourly coverage ratios are then integrated in order to obtain the overall coverage ratio. The calculation of this indicator allows a statement about the autonomy of the settlement area.

$$
\begin{gathered}
C R=\frac{100}{8760} \cdot \int_{t=0}^{8760} C R_{t} \cdot d t \#(5) \\
H D_{S A, t} \geq E H_{B G P, t} \Rightarrow C R_{t}=\frac{E H_{B G P, t}}{H D_{S A, t}} \#(6) \\
H D_{S A, t}<E H_{B G P, t} \Rightarrow C R_{t}=1 \#(7)
\end{gathered}
$$

\subsection{Allocation of the biogas plants to CLC areas}

As described in section 3.2, the shape files of the CLC settlement areas and the coordinates of the biogas plants were used in the geoinformation system QGIS. After the calculation of the centroids of the CLC areas, QGIS was used to calculate the distance matrices for the distances between biogas plants and CLC areas as well as for the distances between the CLC centroids. In the first case, the closest 50 CLC areas and their distances to each biogas plant were determined. In the latter case, due to computational restrictions, only the closest 25 CLC areas were determined for each of the 38,414 CLC areas. Our results indicate that the limitation to the next 25 or 50 areas is sufficient. The distances are needed to calculate the costs of the DHPs, as will be explained in the following sections.

Now the loop shown in the algorithm in Figure 1 after determining the distance matrices is explained. In the first step, $\mathrm{CO}_{2}$ abatement costs/payback periods are calculated for each of the 10,446 biogas plants, which would result from the supply of $\mathrm{DH}$. This is done for every biogas plant for all 50 of the closest CLC areas. In the next step, the connection is selected from the resulting $10,446 \times 50$ connections, which results in the lowest $\mathrm{CO}_{2}$ abatement costs/payback period. Then the 25 closest CLC areas to the selected CLC area are added to the selected biogas plant because this CLC area can now be considered as the starting point for the heat supply. The amount of heat provided to the settlement is deducted in the next steps from the heat supply of the biogas plant and from the heat demand of the settlement. The maximum possible amount of heat is provided in each step. If there is no heat supply left after this step, the biogas plant will be removed from consideration, otherwise the CLC area. The abort criterion is then checked, and if the last $\mathrm{CO}_{2}$ abatement costs/payback period are above a predefined limit value, the loop is aborted. The limit values are described in more detail in section 4. Otherwise the loop is carried out again, but the recalculation is carried out only for the biogas plants and CLC areas where the heat supply or heat demand has changed since the last iteration, in order to reduce simulation time. In addition, all variables that change are recalculated, such as $C R$ and $S R$ from section 3.3.3. All biogas plants that have the selected CLC area among the nearest 50 areas will therefore be included in the new calculation. In each step, for economic reasons it is ensured that the total length of the DHP does not exceed 50 km (Arbeitsgemeinschaft QM Fernwärme 2017). 
The following sections explain the determination of the $\mathrm{CO}_{2}$ emissions saved (section 3.4.1), the costs for the $\mathrm{DHN}$ and the $\mathrm{CO}_{2}$ abatement costs (section 3.4.2) as well as the payback period (section 3.4.3).

\subsubsection{Calculation of the saved $\mathrm{CO}_{2}$ emissions}

The calculation of the saved $\mathrm{CO}_{2}$ emissions is based on the allocation of used energy to provide heat to the settlement areas. The emission factors (EF) of the energy sources and their average allocation in Germany are shown in Table 2. The allocation of the energy for the determination in the settlement areas is based on the average values in the respective federal state (Statistisches Bundesamt 2016a). Since the shares of $\mathrm{DH}$, wood pellets, biomass, solar energy and geothermal and other environmental heat in the total heat demand are deducted from the total heat demand (cf. section 3.3.1), these types of energy are not listed in Table 2.

Table 2: The emission factors EF of the heating energy sources and their average allocation in Germany (LfU 2016; Statistisches Bundesamt 2016a).

\begin{tabular}{lll}
\hline Energy carrier & Allocation A [\%] & Emission factor EF [kg/kWh] \\
\hline Gas & 62.50 & 0.252 \\
Heating oil & 31.84 & 0.315 \\
Electricity (EL) & 4.90 & 0.646 \\
Brown coal (BC) & 0.54 & 0.429 \\
Hard coal (HC) & 0.22 & 0.428 \\
\hline
\end{tabular}

The calculation of the saved $\mathrm{CO}_{2}$ emissions $\mathrm{CO}_{\text {saved,SA }}$ in Eq. 8 is based on the calculated coverage ratios per settlement area $C R_{S A}$. Excess heat replaces part of the fossil energy used to supply the settlement areas. It is assumed that excess heat replaces the existing energy carriers proportionally. The usage of excess heat has an emission factor of $0 \mathrm{~kg} / \mathrm{kWh}$ (Theissing 2012).

$$
C O 2_{\text {saved }, S A}=\frac{H D_{S A} \cdot C R_{S A} \cdot\left(A_{G a s} \cdot E F_{G a s}+A_{O i l} \cdot E F_{O i l}+A_{E L} \cdot E F_{E L}+A_{B C} \cdot E F_{B C}+A_{H C} \cdot E F_{H C}\right)}{1000} \#(8)
$$

\subsubsection{Determination of the $\mathrm{CO}_{2}$ abatement costs}

The investment for the $\mathrm{DH}$ grid construction, or densification in case a DHN already exists, are mainly based on the length of the grid. The grid length cannot be determined without a detailed on-site investigation or analysis of the heat demand density/distribution using a geographic information system. Persson \& Werner (2011) developed a method to determine the investment for $\mathrm{DH}$ grids without the mentioned procedures. In this way, the investment can be estimated based on publicly available data such as population density, specific building space, specific heat demands and some cost parameters.

First, the fraction of the excess heat that is supplied by the biogas plant to the settlement area $Q_{\text {sell }}$ is determined using Eq. 9.

$$
Q_{\text {sell }}=H D_{S A} \cdot C R \#(9)
$$

The investment $I_{D H G, S A}$ for the building or the densification of the district heating grid (DHG) in a settlement is determined by the specific heat distribution costs $H D C_{S A}$ and the excess supplied heat $Q_{\text {sell }}$. In Section A.4 of the appendix, a detailed description of determining the 
specific heat distribution costs $H D C_{S A}$ in the settlements is given. Additionally, the investment in the pipeline for connecting the biogas plant and the settlement area $I_{c o n, S A}$ has to be calculated. There an investment rate $I R$ of $200 € / \mathrm{m}$ for the pipe is multiplied by the distance $D I S_{S A}$ between biogas plant and settlement area (Fraunhofer UMSICHT 1998; C.A.R.M.E.N. e.V 2012; Pfnür et al. 2016). The relatively low value of $200 € / \mathrm{m}$ is supposed to reflect the fact that biogas plant operators receive a subsidy in the context of the Combined Heat and Power Act (KWKG) amounting to $100 € / \mathrm{m}$ of DHN built (BMJV 2018). Finally, the investment can be summed up in Eq. 10 and results in the necessary investment $I_{S A}$ to use the excess heat from the biogas plant to supply the settlement area with heat.

$$
I_{S A}=I_{D H G, S A}+I_{\text {con }, S A}=H D C_{S A} \cdot Q_{\text {sell }} \cdot 0.0036+I R \cdot D I S_{S A} \#(10)
$$

The multiplication by 0.0036 is performed to convert $Q_{\text {sell }}$ to GJ. In the section 3.4 .1 , the saved $\mathrm{CO}_{2}$ emissions were determined. These are now taken into account to calculate the specific $\mathrm{CO}_{2}$ abatement costs $\mathrm{CO}_{\text {costs }}$ (cf. Eq.11).

$$
C O 2_{\text {costs }}=\frac{I_{S A}}{C O 2_{\text {saved }, S A}} \#(11)
$$

\subsubsection{Determination of the net present value and payback period}

The net present value (NPV) is used as a further economic criterion and is calculated using Eq.12 using the sum of the discounted revenues $R E V_{S A}$ less expenses $E X P_{S A}$. Discounting over a certain period is taken into account by the discounting factor $d f$ of $0.05(5 \%)$, which is intended to represent a compromise between social and commercial discount rates. Finally, the investment $I_{S A}$ is deducted to calculate the $N P V_{S A}$. Annual costs are caused by maintaining the $\mathrm{DHG}$ and driving the $\mathrm{DH}$ pumps. As operating power of the pumps, a factor $P_{p}$ of $10 \mathrm{kWh}_{\mathrm{el}} / \mathrm{MWh}_{\mathrm{th}}$ is used (Good 2004). This means that $10 \mathrm{kWh}_{\mathrm{el}}$ is required for each $\mathrm{MWh}_{\mathrm{th}}$ of $\mathrm{DH}$ transported to drive the pump. Revenue is generated by selling heat to the customers. The used input data is shown in Table 3, which gives the mean heat prices from a random sample of ten district heat providers in Germany.

$$
N P V_{S A}=\sum \frac{R E V_{S A}-E X P_{S A}}{(1+d f)^{t}}-I_{S A} \#(12)
$$

The NPV is not a key result for this analysis, but is used to determine the payback period $P P$ of the excess heat utilisation. In the algorithm, a loop is used to identify the time $t$ at which the NPV becomes positive.

Table 3: Input data for economic evaluation, (Statista 2018a, BDEW 2018, SWB 2014).

\begin{tabular}{lrr}
\hline Asset & Costs & Units \\
\hline Maintenance cost rate of the DHG & 0.5 & $\%$ of investment \\
Electricity purchase price EP & 0.2324 & $€ / \mathrm{kWh}$ \\
Thermal connection power Pa & 5 & $\mathrm{~kW}$ \\
Heat selling prices HS: & & $€ / \mathrm{kWh}$ \\
$\quad$ Energy price & 0.0664 & $€ / \mathrm{kW}$ \\
Demand charge & 30.99 & $€ /$ month \\
Base price & 10.81 & \\
\hline
\end{tabular}




\section{Results and discussion}

In this section, the algorithm is validated before the results are discussed in more detail (cf. section 4.1). Initially, the calculations are only carried out with 241 biogas plants included in the survey. Section 4.2 demonstrates how these 241 plants were selected. Thereafter, it will be shown in section 4.3 how the results change when all 10,446 biogas plants in Germany are included in the analysis. In order to provide the algorithm with appropriate abort criteria, the limit value of the $\mathrm{CO}_{2}$ abatement costs is set in all calculations to $1,000 € / t \mathrm{CO}_{2}$, the limit value of the payback period to 20 years. The reason for these high values is that we wish to economically assess the technical potential, rather than to directly determine an economic potential based on some predefined criteria. Finally, the procedure is critically appraised in section 4.4. The algorithm was implemented in MATLAB and solved using a standard desktop PC (2x Intel Xeon 5430 Processor and 24 GB RAM). The solution time for the 241 plants is around ten minutes and that for the whole German biogas plant stock about two days. The code can be made available by the authors upon request.

\subsection{Validation of the algorithm}

Figure 3 gives an overview of the possible types of $\mathrm{DH}$ connections that can be created by the algorithm in Figure 1. The red DHPs lead from a biogas plant to a settlement area and the blue ones lead from one settlement area to another. The black lines represent municipal borders. The results shown in this figure were derived from the calculation with all biogas plants in Germany and the $\mathrm{CO}_{2}$ abatement costs as a selection criterion (cf. scenario A.1 in section 4.3). The first case shows biogas plant 7 (number in box), which has no connection to a settlement area. This can have several reasons. On the one hand, $100 \%$ of the excess heat from the biogas plant could already be used. In this case, this biogas plant would be one of the 241 plants from the survey, since only in these plants over $60 \%$ heat is used (cf. section 4.3). On the other hand, the settlement area in the vicinity could have no heat demand, e.g. because all buildings are already supplied with heat from alternative technologies. In addition, a DH supply might not be worthwhile in this case, since the limit values of the target criteria are exceeded in the algorithm. The second case is the one in which a settlement area is supplied with $\mathrm{DH}$ by only one biogas plant, and these biogas plants also supply only one settlement area (biogas plants 3 and 8 ). If a settlement area is supplied by several biogas plants, this is the third case (biogas plants 1, 2, 5, 6 and 9). The fourth case is the supply of several settlement areas by a biogas plant, as in the case of the biogas plants 4, 5 and 6 . Finally, the connections of biogas plant 5 show that the DHP can also lead from one settlement area to the next, as shown by the blue-coloured DHP. 


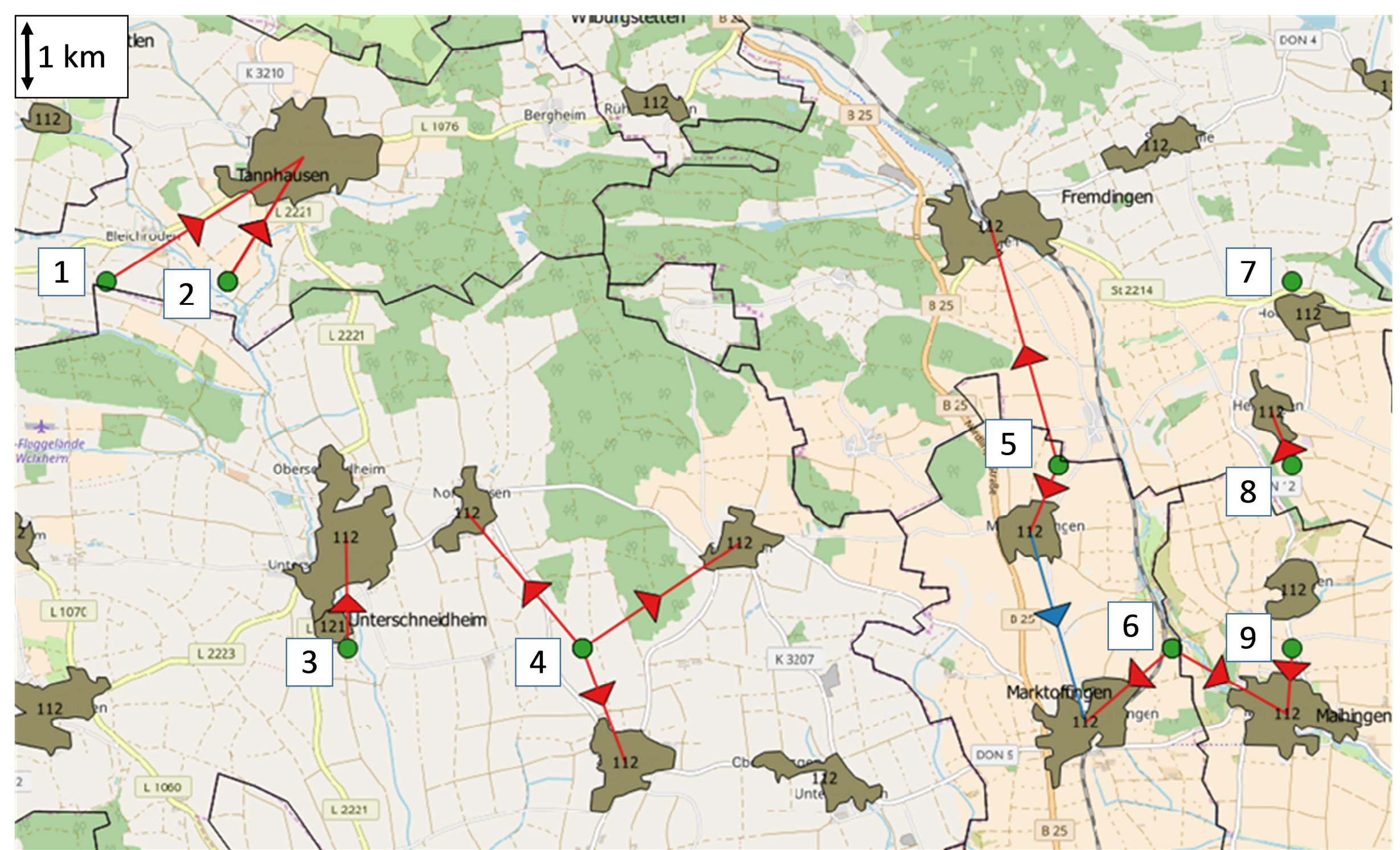

Figure 3: Exemplary illustration of resulting DHPs for the use of excess heat from biogas plants in several municipalities in Baden-Württemberg. The background map is from OpenStreetMap contributors (2018). 
The heat demand of the settlement areas from section 3.3.1 can also be validated. The sum for all settlement areas $H D_{S A_{\text {total }}}$ results in a heat demand of $576 \mathrm{TWh}$ (cf. Eq. 18 in the appendix). The heat demand for space heating and hot water in private households (mainly gas demand, cf. DIW Berlin \& EEFA 2017) is subject to large annual fluctuations (Umweltbundesamt 2017a) and ranged from 544 to 578 TWh between 2010 and 2015 (Statista 2018b). In 2010, from when the census data, heat consumption data and renovation data originate, the heat requirement was 578 TWh (Deviation: $-0.35 \%$ ). Thus, the procedure presented in section 3.3.1 can be deemed to be very accurate.

\subsection{Results from the survey}

In the survey, respondents provided information on the percentage share of heat utilisation for different categories such as in schools, hospitals and fish farming. In 262 of the 602 plants, the total shares were above $100 \%$ (cf. Figure 4). The plants with a heat utilisation of more than $100 \%$ are excluded from the analysis in this study, as it seems the survey participants misunderstood the questions and/or made mistakes in stipulating these shares. In total, this results in an average heat utilisation of $60 \%$ and an unused heat fraction of $40 \%$.

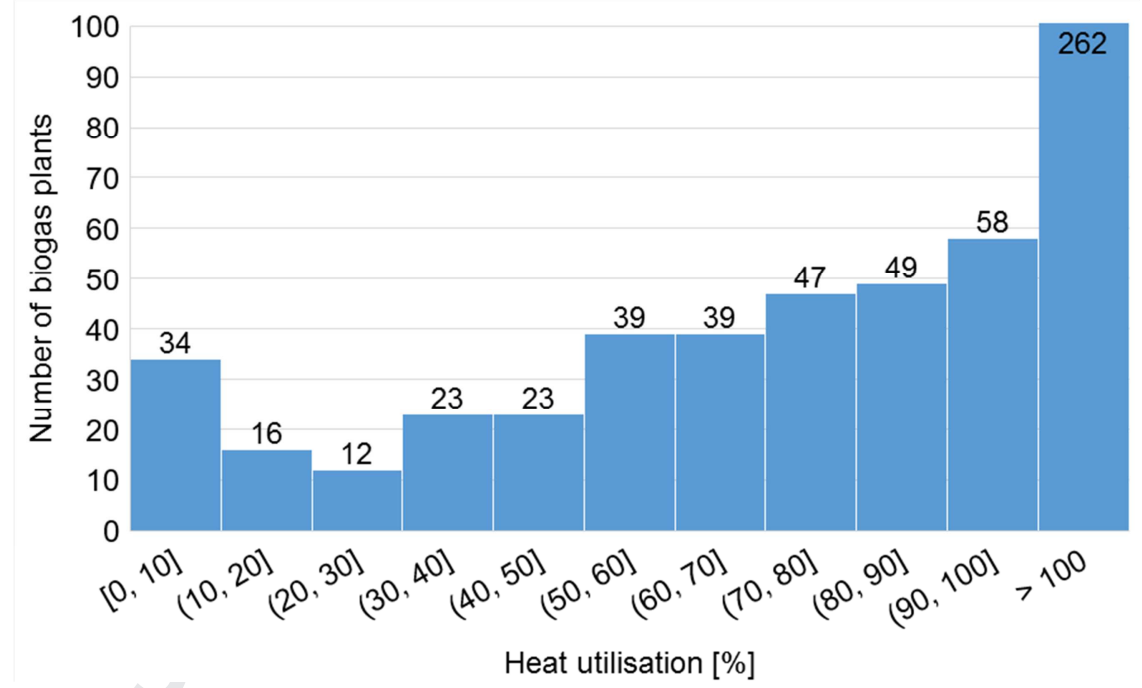

Figure 4: Number of biogas plants surveyed as a function of the specified share of heat that is already being used.

Of the 602 biogas plants from the survey, 241 plants (40\%) could be identified and mapped in the Energymap plant register (cf. section 3.2). 111 of the 241 plants, however, are among the 262 plants in which a heat utilisation value of above $100 \%$ was reported. As the left part of Figure 5 shows, the majority of the 241 biogas plants (green circles) identified are located in the federal state of Bavaria (143 plants $\triangleq 59 \%$ ). This also corresponds to the distribution of the responses from the survey (cf. section 3.1). 

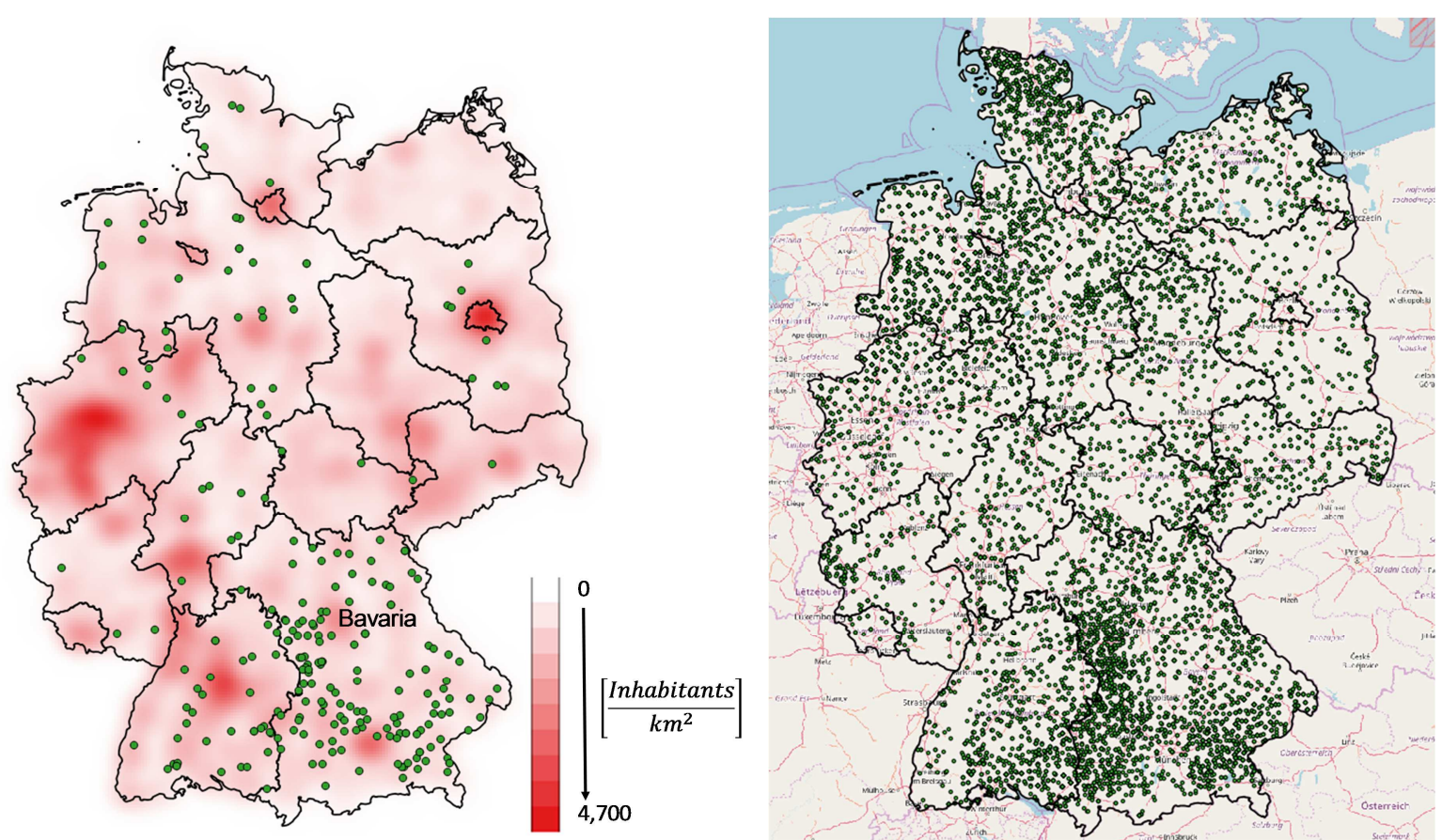

Figure 5: Location of the 241 biogas plants identified among the plants surveyed in Germany and a heat map showing the population density in the settlements (left part). Location of all biogas plants in Germany (right part) (Engel 2015; Statistisches Bundesamt 2017c).

The heat map on the left side of Figure 5 shows the population density. White areas mark settlements with a low population density and the population density then rises to dark red. The heat map shows that the calculation with only 241 plants does not take into account the settlements with the highest population densities. A comparison of the 241 plants with all plants in Germany (cf. right part of Figure 5) shows that the latter are clearly more evenly distributed across Germany. Of the 241 biogas plants allocated, only 121 plants still have unused heat. The remaining 120 plants already use $100 \%$ of their excess heat.

First of all, the results of the calculations with $\mathrm{CO}_{2}$ abatement costs as a decision criterion are presented in section 4.2.1, followed by the results of the calculations with payback period as a decision criterion in section 4.2.2. A sensitivity analysis is performed for both cases to show how some key parameters affect the results. The values of the parameters were changed in $10 \%$ steps from $-50 \%$ to $+50 \%$. The only exception is the distance of the biogas plant from a specified location. As described in section 3.1, the location of the biogas plant can have a maximum uncertainty of $3 \mathrm{~km}$. The smallest distance between a biogas plant and the centroid of a settlement area is 10 metres, which lies far below this maximum uncertainty. However, it can also be a so-called satellite CHP unit located within the settlement area (Rutz \& Güntert 2012). After all, $17 \%$ of the biogas plant operators in Germany have a satellite CHP unit (Liebetrau et al. 2017). To cover this uncertainty, the distance of the plants to the settlement areas was varied between $-3 \mathrm{~km}$ to $+3 \mathrm{~km}$. Since this parameter is shown together with the other parameters in Figure 6 below, $-3 \mathrm{~km}$ corresponds to $-50 \%$ and $+3 \mathrm{~km}$ to $+50 \%$ and the change of $10 \%$ corresponds to 600 meter steps. A further examination of over 700 plants in the most recent EEG biogas plant register from Bundesnetzagentur (2018) enabled them to be matched to their records in Energymap (Engel 2015). The average distance between the matched plants was $1.5 \mathrm{~km}$, which corresponds to a range in Figure 6 of $+/-25 \%$, but it is unclear which of these two sources is more accurate. 


\subsection{1. $\mathrm{CO}_{2}$ abatement costs as decision criterion}

In the reference scenario, defined by the parameter values from section 0 , the $\mathrm{CO}_{2}$ abatement costs range from $55 € / \mathrm{tCO}_{2}$ to $987 € / \mathrm{tCO}_{2}$ (mean: $120 € / \mathrm{tCO}_{2}$ ) and $41,500 \mathrm{tCO} / \mathrm{a}$ is saved. 129 DHPs are built in this case.

Figure 6 shows the mean $\mathrm{CO}_{2}$ abatement costs resulting from the sensitivity analyses. The strongest deviation occurs when the coordinates of the biogas plants are changed (distance of biogas plant from specified location). The mean $\mathrm{CO}_{2}$ abatement costs change by $-41 \%$ if the biogas plants are $3 \mathrm{~km}$ closer to the settlement areas and by $+97 \%$ if the biogas plants are $3 \mathrm{~km}$ further away from the settlement areas. The deviation for the $3 \mathrm{~km}$ closer plants is smaller, since some plants are already less than $3 \mathrm{~km}$ away from the settlement areas. The gradient of the curve becomes more constant the less the distance is reduced. Nevertheless, the curves do not have constant gradients. This is related to the abort criteria, as a result of which more and more connections between plants and settlements are excluded from the analysis or included in the analysis when parameters are changed. This will be further explained in section 4.2.2. If the biogas plants deviate $1.5 \mathrm{~km}$ from their location as described above, the costs could change between $-31 \%$ and $+52 \%$.

The pipe specific investment outside a settlement $I R$ and the discount factor $d f$ have approximately the same effect on the mean $\mathrm{CO}_{2}$ abatement costs and reduce them by a maximum of $19 \%$ at $-50 \%$ and increase them by a maximum of $19 \%$ at $+50 \%$. It is interesting to note that the pipe specific investment inside a settlement $H D C_{S A}$ has a stronger effect on costs than $I R$. This means that the DHPs within a settlement have a greater influence on costs than the DHPs leading to the settlement, i.e. the population density of a settlement is of crucial importance. The same conclusion can be drawn when looking at the curve of the plot ratio $e$. This is the only parameter that leads to a reduction of the average cost when it is increased. An increase of $e$ is equivalent to an increase of the building density in the settlements. In this case, more heat can be delivered per settlement area that would otherwise remain unused.

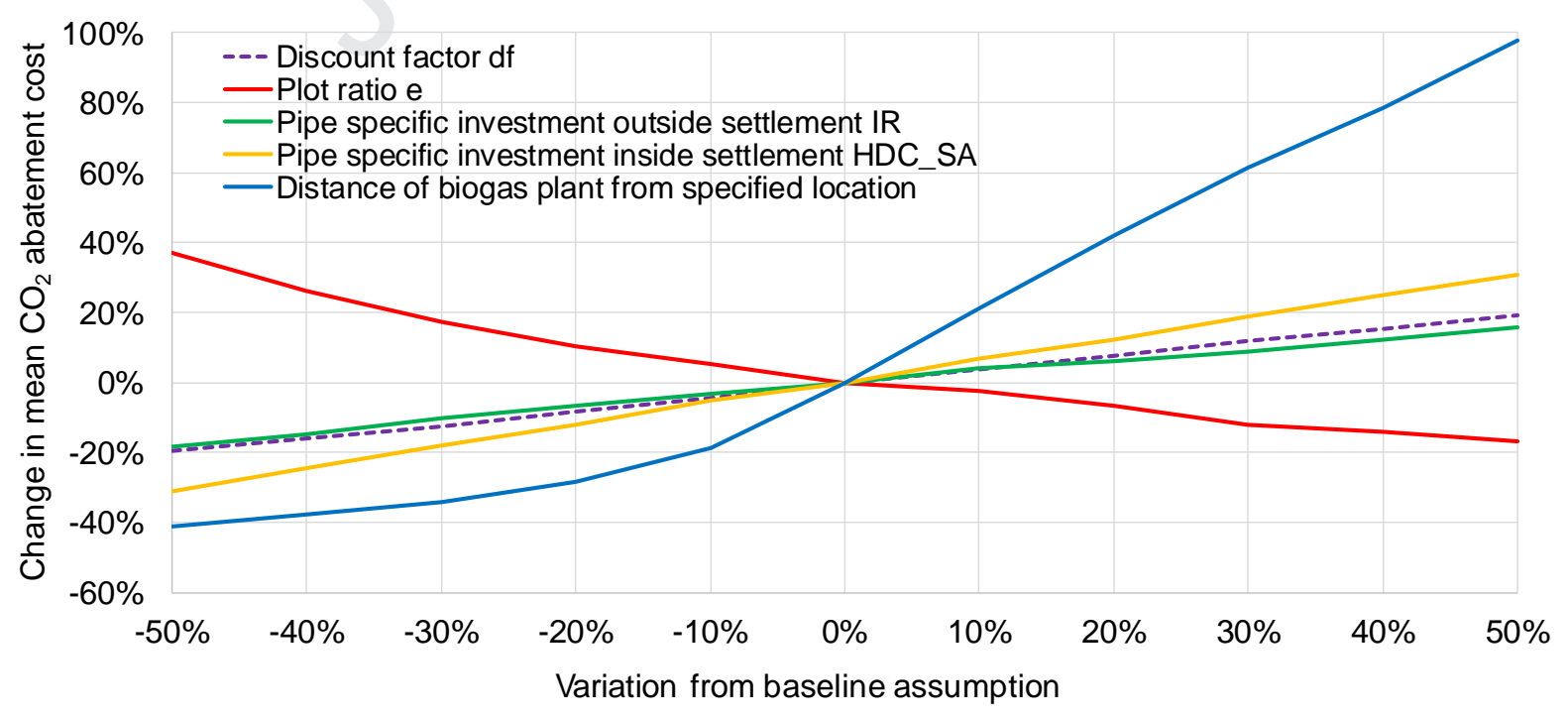

Figure 6: Change in the mean $\mathrm{CO}_{2}$ abatement costs of the reference scenario when changing specific parameters. 
As illustrated in Figure 7, the variation of the parameters does not have a large influence on the total $\mathrm{CO}_{2}$ abatement. The change in total $\mathrm{CO}_{2}$ abatement of the reference scenario $\left(41,483 \mathrm{tCO}_{2} / \mathrm{a}\right)$ varies only between $-1.5 \%$ and $+0.5 \%$. The greatest influence has once again the variable "distance of biogas plant from specified location".

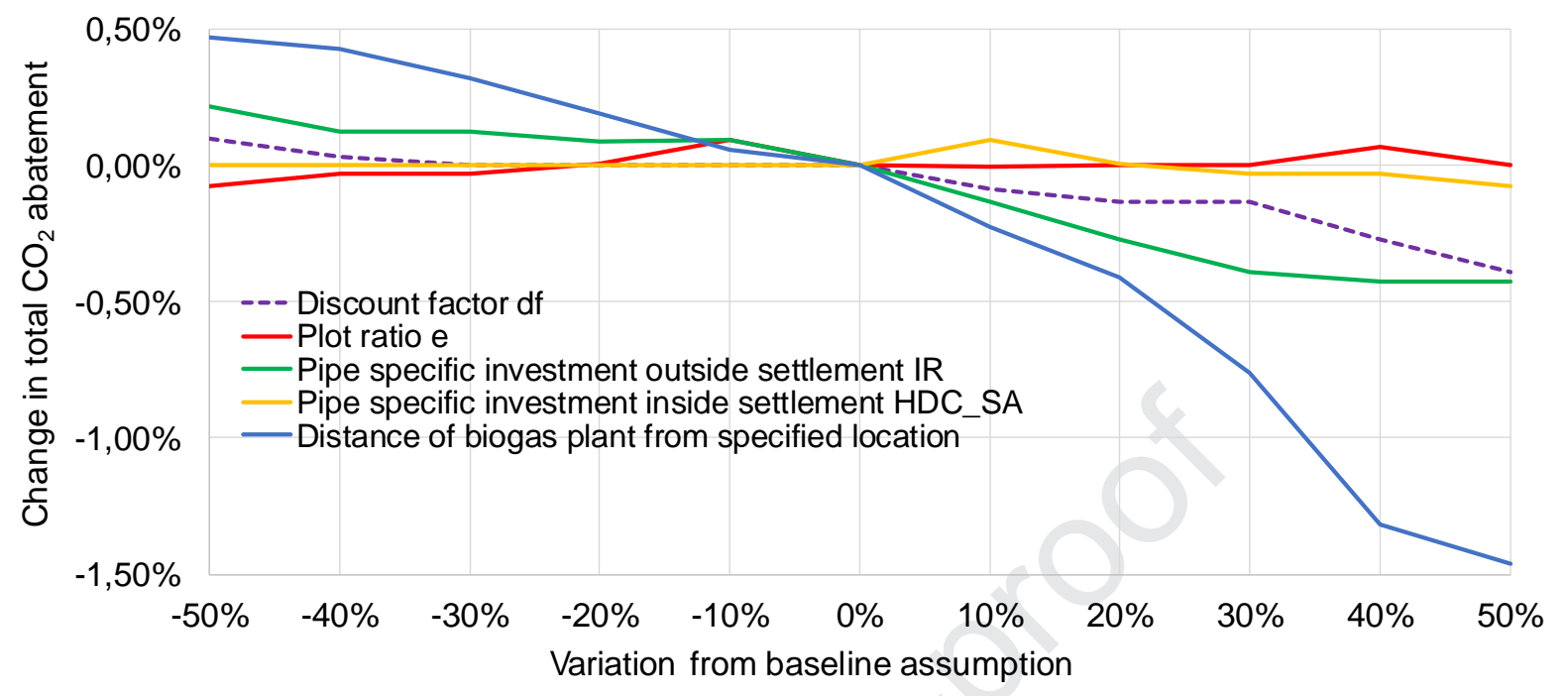

Figure 7: Change in the total $\mathrm{CO}_{2}$ abatement of the reference scenario when changing specific parameters.

Some of the curves in Figure 7 are not linear, which would not be directly suspected. For example, it has been concluded that an increase of the plot ratio $e$ continuously reduces the $\mathrm{CO}_{2}$ abatement costs. It is also likely that an increase of $e$ would increase the total $\mathrm{CO}_{2}$ abatement. However, the curve in Figure 7 shows that, for example, with an increase of $e$ from $+40 \%$ to $+50 \%$, the total $\mathrm{CO}_{2}$ abatement decreases again (by $28 \mathrm{tCO}_{2} / \mathrm{a}$ ). This example is now explained on behalf of the other non-linearities in Figure 7. In the case of $+40 \%$, a biogas plant in a municipality in Bavaria will initially supply the CORINE area 8940 with $485 \mathrm{tCO}_{2} / \mathrm{a}$ for $108 € / \mathrm{tCO}_{2}$ and later on a connection to the CORINE area 8876 will be installed with $65 \mathrm{tCO}_{2} / \mathrm{a}$ for $345 € / \mathrm{tCO}_{2}$ (cf. left part of Figure 8). In the case of $+50 \%$, the CORINE area 8876 will be selected directly with $522 \mathrm{tCO}_{2} /$ a for $105 € / \mathrm{tCO}_{2}$ (cf. right part of Figure 8). 

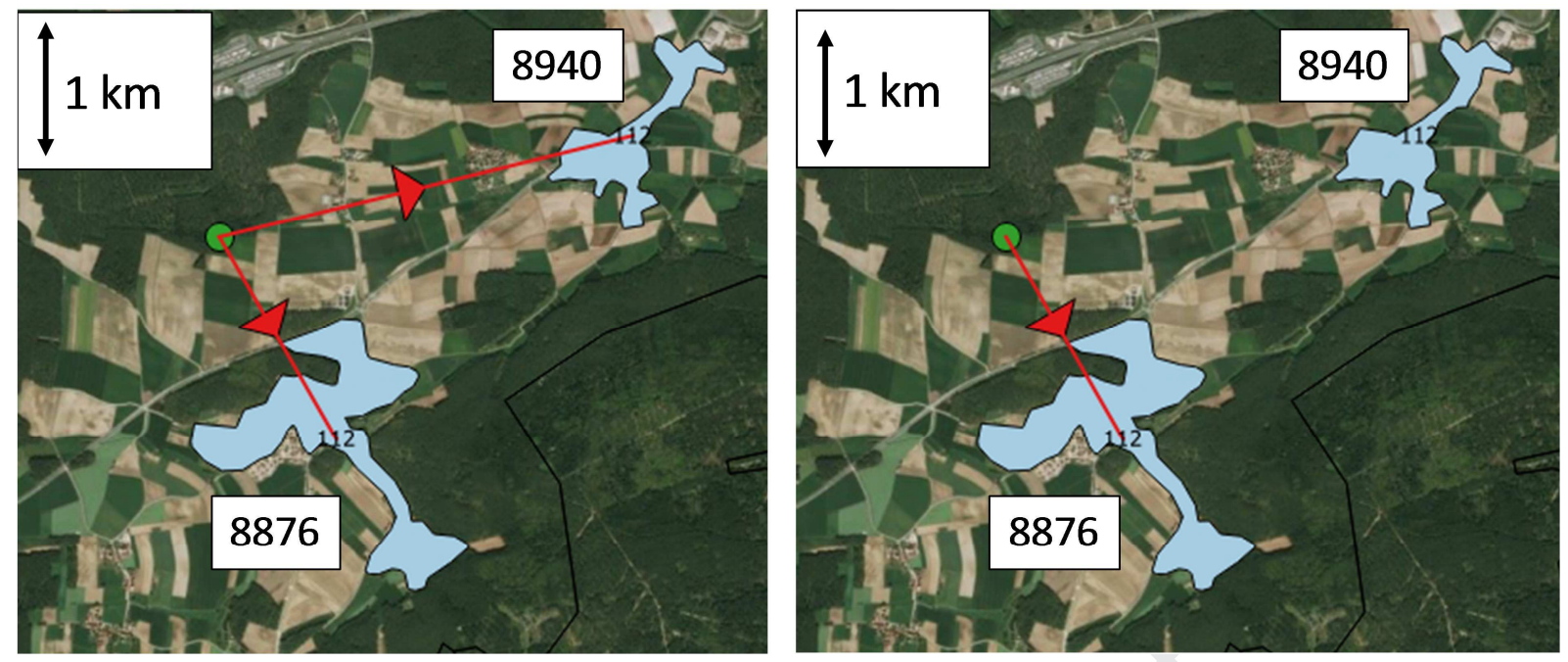

Figure 8: DHN for the utilisation of the excess heat from a biogas plant in a municipality in Bavaria. The left part of the figure shows the connections that result in the case where plot ratio e is increased by $40 \%$, in the right part $e$ is increased by 50\%. The background map is from Microsoft (2018).

In the first case, CORINE area 8876 is also supplied, since approx. $14 \%$ of the excess heat in the biogas plant remains after supplying CORINE area 8940. In the second case, however, only $7.4 \%$ excess heat is left after supplying CORINE area 8876 , so that the supply of area 8940 is no longer worthwhile $\left(\mathrm{CO}_{2}\right.$ abatement costs of $\left.1,180 € / \mathrm{tCO}_{2} \geq 1,000 € / \mathrm{tCO}_{2}\right)$. The reason for the fact that settlement area 8940 is supplied before area 8876 (up to case $+50 \%$ ), although in settlement area 8876 there is more heat demand, is, among other things, the almost twice as high population density in settlement area 8940 (3,400 persons per km² compared to 1900 persons per $\mathrm{km}^{2}$ ). In order to avoid fluctuations in the curves of the total $\mathrm{CO}_{2}$ abatement costs in Figure 7, the total $\mathrm{CO}_{2}$ abatement costs would have to be used as a decision criterion in the algorithm. In this case, however, the $\mathrm{CO}_{2}$ abatement costs involved could be excessively high in some cases.

\subsubsection{Payback period as decision criterion}

If the payback period is selected as the decision criterion, the reference scenario results in a mean payback period of 7.2 years (payback periods of between 2.5 and 20 years). In this case, 122 DHPs are built and 40,600 $\mathrm{tCO}_{2} / \mathrm{a}$ is saved.

The mean payback period increases the most when HS decreases $(+69 \%)$ and is the lowest when the distance of biogas plant from specified location decreases $(-44 \%$, cf. Figure 9$)$. If HS decreases, only a lower profit can be achieved by selling the heat. Since the variation of $\mathrm{DH}$ pump power $P_{p}$ has exactly the same effect on the payback period, only the electricity price EP is shown in the figure (cf. section 3.4.3). If EP increases, the costs for driving the $\mathrm{DH}$ pumps and thus the payback period increase. $P_{a}$ has an opposite effect on the payback costs, since the rate at which the heat is delivered, and hence the amount of heat sold, depends strongly on this parameter. The distance, $e, d f, H D C_{S A}$ and $I R$ have almost the same effect on the mean payback period as on the mean $\mathrm{CO}_{2}$ abatement costs (cf. section 4.2.1). 


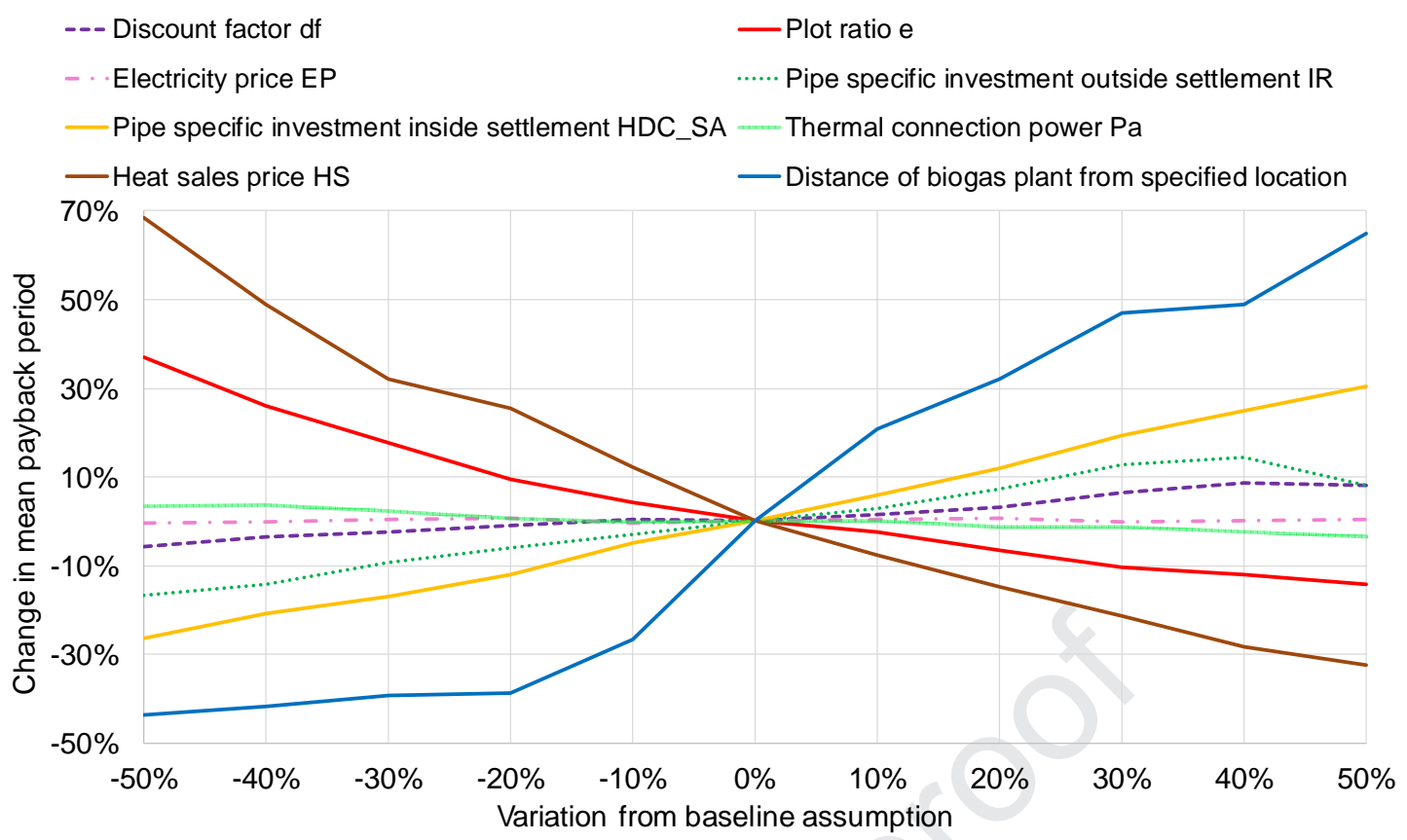

Figure 9: Change in the mean payback period of the reference scenario when changing specific parameters.

However, the declining mean payback period with a change from $I R$ from $+40 \%$ ( 8.3 years) to $+50 \%$ ( 7.8 years) is remarkable. The other non-linearities in the curves in Figure 9 can also be explained using the following example: Figure 10 shows the change in the number of DHPs when increasing $I R$ from $-50 \%$ to $+50 \%$. The number of connections is reduced from 132 at $-50 \%$ to 107 at $+50 \%$. In each step, the changes are within a range of one to three no longer existing connections. However, in the last step from $+40 \%$ ( 115 connections) to $+50 \%$ (107 connections), eight connections no longer exist due to a payback period of more than 20 years. As a result, many of the connections with a long payback period will be eliminated in this step. Therefore, the mean payback period decreases in this case. This can be proven by repeating the calculation in the case of $+50 \%$, and this time not using the payback period as a criterion for aborting the algorithm, but by aborting at a number of 115 DHPs as in case $+40 \%$. This would result in a mean payback period of 8.8 years, which is higher than in the case of $+40 \%$.

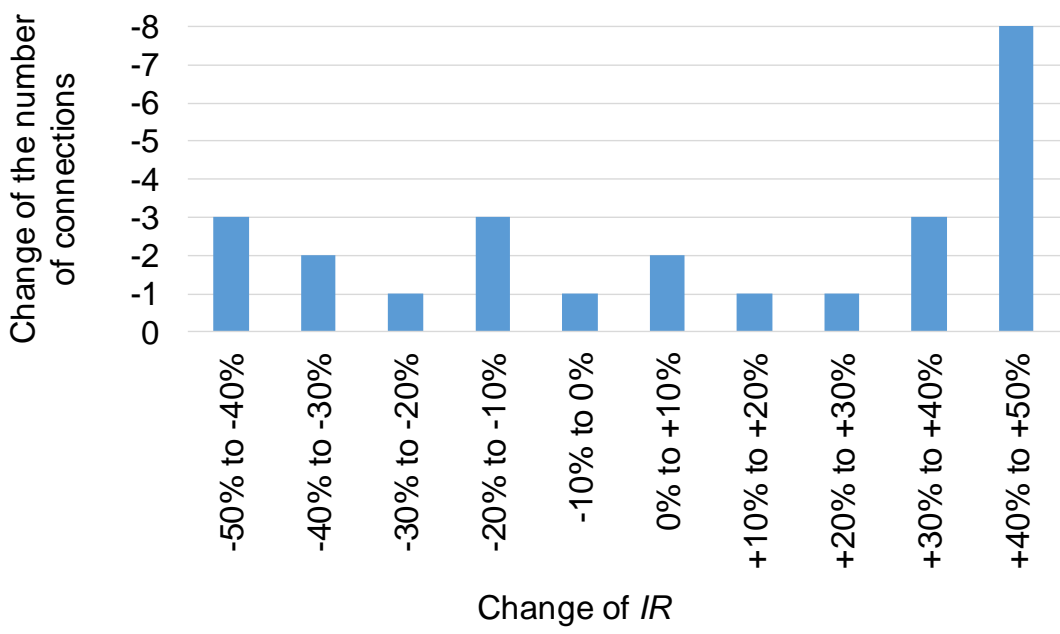

Figure 10: Change in the number of DHPs when changing IR. 


\subsection{Results for all German biogas plants}

The analysis with all 10,446 biogas plants assumes an average value of $40 \%$ unused heat in the biogas plants that were not part of the survey (cf. section 3.1). Whilst there will obviously be deviations in individual cases, the assumption of $40 \%$ excess heat seems reasonable and is verified by other studies (e.g. DBFZ 2015). Table 4 shows the various scenarios developed with all biogas plants.

Table 4: Overview of the scenarios carried out with all biogas plants.

\begin{tabular}{lll}
\hline Number & Decision criterion & Adjustment \\
\hline A.1 & $\mathrm{CO}_{2}$ abatement costs $<1,000 € / \mathrm{tCO}_{2}$ & - \\
A.2 & $\mathrm{CO}_{2}$ abatement costs $<1,000 € / \mathrm{tCO}_{2}$ & Not considering Eq. 1 \\
A.3 & $\mathrm{CO}_{2}$ abatement costs $<1,000 € / \mathrm{tCO}_{2}$ & New excess heat profile, cf. Figure 12 \\
B.1 & Payback period $<20$ years & - \\
& Payback period $<20$ years & $\begin{array}{l}\text { Considering the cogeneration bonus } \\
\text { of } 3 \mathrm{ct} / \mathrm{kWh} \text { for district heat from } \\
\text { biogas plants }\end{array}$ \\
B.2 & & biog \\
\end{tabular}

When using the $\mathrm{CO}_{2}$ abatement costs as a decision criterion in scenario A.1, the excess heat from 9,790 different biogas plants is used. A total of 10,989 DHPs are built in this case and $2.55 \mathrm{MtCO}_{2} / \mathrm{a}$ can be saved (cf. yellow line Figure 11). This corresponds to $0.3 \%$ of the amount of $\mathrm{CO}_{2}$ emitted in Germany in 2015, equivalent to $792 \mathrm{MtCO}_{2} /$ a (Umweltbundesamt 2017c). $85 \%$ of the $2.55 \mathrm{MtCO}_{2} /$ a can be saved with $\mathrm{CO}_{2}$ abatement costs below $200 € / \mathrm{tCO}_{2}$. The first $78 \mathrm{tCO}_{2}$ are saved at a minimum cost of $13.5 € / \mathrm{tCO}_{2}$, which is $41.5 € / \mathrm{tCO}_{2}$ less than the best connection in the case of the 241 plants. The reason for this is that this biogas plant is located only 70 metres from the settlement area centroid. In total, around 8 TWh of heat demand in German households are covered by the biogas plants.

Scenario A.2 assumes that the biogas plant can replace all forms of existing heat supply (i.e. neglecting Eq. 1, so $\left.H D_{S A}=H D_{S A_{\text {total }}}\right)$. In this case, the $\mathrm{CO}_{2}$ abatement is only $5 \mathrm{ktCO}_{2} / \mathrm{a}$ higher at almost the same cost. This can be explained as follows. At the beginning of the calculation with all plants, approx. 10 TWh of excess heat are available from all biogas plants. In the end of calculation A.1 above, only 0.22 TWh (2\%) remain at the end. This shows that there is scarcely any potential for an increase and that there is a bottleneck on the supply side of the biogas plants, rather than on the demand side in the existing heat supply systems. For the second scenario (without Eq. 1) only 0.03 TWh more heat is used, due to the small amount of non-fossil-fuel-based existing heating that is replaced in this case. Since the $\mathrm{CO}_{2}$ abatement cost curve does not change significantly, the curve for A.2 is not shown in Figure 11. The bottleneck on the supply side of the biogas plants explains the lower $\mathrm{CO}_{2}$ abatement here than in Soltero et al. (2018) (cf. section 2.2). In their study, $5.4 \mathrm{MtCO}_{2}$ were avoided, however, the entire heat of biomass plants was used instead of unused excess heat as in our study. 
Journal Pre-proof

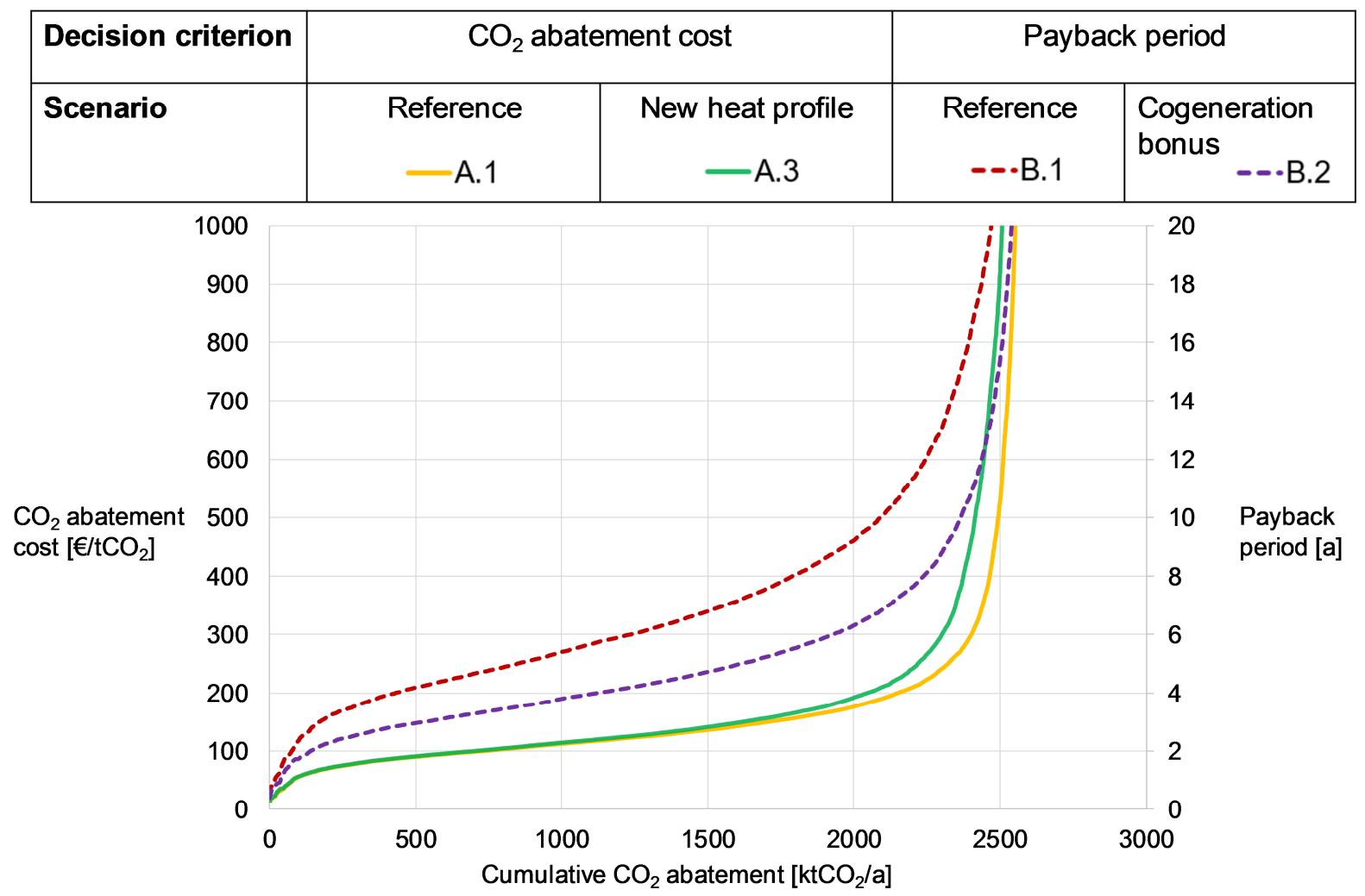

Figure 11: Cumulative $\mathrm{CO}_{2}$ abatement in the scenarios with $\mathrm{CO}_{2}$ abatement costs or payback period as the decision criterion. The curves refer to the $y$-axes with the corresponding decision criterion of the scenario.

As explained in section 3.3.2, a constant load profile for the excess heat from the biogas plants was assumed. However, this profile could look different in reality, since the digester or residential buildings that are already supplied with heat require more heat in the colder months (Rutz et al. 2015). Based on the values from Rutz et al. (2015), the load profile of a biogas plant that supplies residential buildings and the digester with excess heat is changed in scenario A.3 according to Figure 12. The short period in summer, in which the load is $0 \mathrm{~kW}$, is due to the fact that the biogas plant shown as an example has full load hours of less than 8760 .
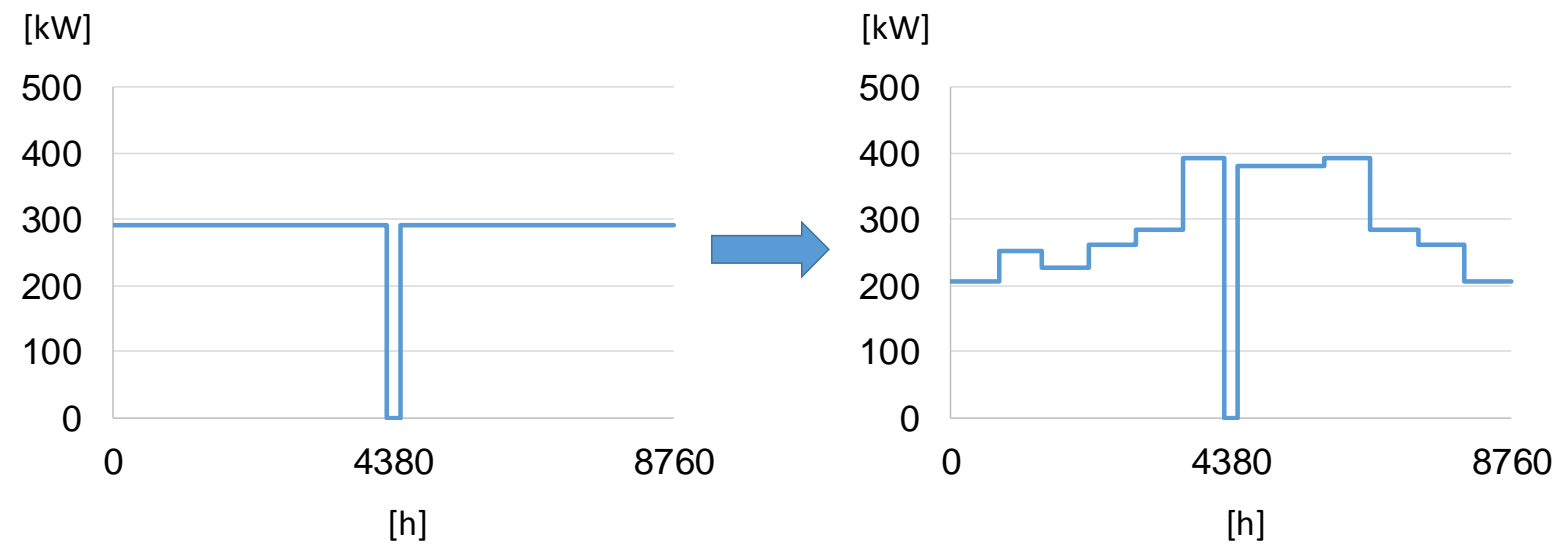

Figure 12: Change in excess heat load profile, without (left) and taking into account monthly differences in heat utilisation (right).

Actually, curve A.3 would be expected to differ significantly from curve A.1, as more heat is now available in summer, i.e. at a time when less heat is required. However, this is not the case due to the bottleneck in the heat supply of the biogas plants already mentioned in the 
description of scenario A.2. This means that in most cases, however, the settlement areas require more heat in summer than the biogas plants can provide. In total, $5 \mathrm{ktCO}_{2} / \mathrm{a}$ or $0.2 \%$ less is saved than in scenario A.1, with slightly higher mean $\mathrm{CO}_{2}$ costs.

Compared to scenario A.1 with $\mathrm{CO}_{2}$ abatement costs as a decision criterion, if the payback period is used as a decision criterion in B.1, the number of biogas plants whose heat is used decreases by 835 to 8,955 plants and 344 DHPs fewer are built (10,645 pipelines). Overall, $0.08 \mathrm{MtCO}_{2} / \mathrm{a}$ less than in scenario A.1 is saved $\left(2.47 \mathrm{MtCO}_{2} / \mathrm{a}\right)$. The first $85 \% \mathrm{CO}_{2}$ can be saved with a payback period of fewer than 10 years (cf. Figure 11). Only $0.53 \mathrm{TWh}(5 \%)$ of excess heat remains unused in this calculation.

The scenarios discussed above do not include the cogeneration bonus from the Renewable Energy Sources Act 2009, so that B.2 is carried out with the cogeneration bonus in order to estimate its effect on the result. It is assumed that the cogeneration bonus for the heat supply of residential buildings in the amount of $3 \mathrm{ct} / \mathrm{kWh}$ (Clearingstelle EEG 2009) will be paid to all plant operators whose plants were commissioned before 31.12.2011 (Clearingstelle EEG 2012) and have a nominal power of less than 5 MW (Clearingstelle EEG 2009).

Taking into account the cogeneration bonus, the amount of $\mathrm{CO}_{2}$ saved increases by $70 \mathrm{ktCO}_{2} / \mathrm{a}(3 \%)$. This means that the amount cannot be significantly increased due to the above mentioned heat supply bottleneck. However, the mean payback period is considerably shorter than for calculation B.1. Thus, $2 \mathrm{MtCO}_{2} / \mathrm{a}$ are already saved within a payback period of 6 years (instead of 9 years in B.1). This has to be considered as an upper limit, however, as it is not certain whether all biogas plants will receive the cogeneration bonus to the extent assumed here. This is especially the case for plants with a nominal power of more than $500 \mathrm{~kW}$, as they only receive the cogeneration bonus of $3 \mathrm{ct} / \mathrm{kWh}$ for $500 \mathrm{~kW}$ (Clearingstelle EEG 2009). However, the plants commissioned between 2004 and 2008 receive a cogeneration bonus of $2 \mathrm{ct} / \mathrm{kWh}$ regardless of their nominal power (Clearingstelle EEG 2006).

Using the criteria of $\mathrm{CO}_{2}$ abatement costs and payback period, a yield of $2 \mathrm{MtCO}_{2} / \mathrm{a}$ is achieved for values below $200 € / \mathrm{tCO}_{2}$ (A.1) and 9 years (B.1). This corresponds to around $0.25 \%$ of the total German $\mathrm{CO}_{2}$ emissions in 2015 (Umweltbundesamt 2017c) or around $2.5 \%$ of all $\mathrm{CO}_{2}$ in residential buildings (Umweltbundesamt 2017b). The $\mathrm{CO}_{2}$ reduction potential is approximately $0.5 \mathrm{MtCO}_{2}$ and $0.75 \mathrm{MtCO}_{2}$, if thresholds of $80 € / \mathrm{tCO}_{2}$ and 5 years are set to reflect the proposed external cost of carbon and an expected payback period from an investor's point of view respectively (Schwermer 2012). However, if the current price of $\mathrm{CO}_{2}$ in the EU Emissions Trading System of about $7 € / \mathrm{tCO}_{2}$ is taken as a benchmark, the economic fraction of this technical potential saving diminishes to $0 \mathrm{tCO}_{2}$.

Figure 13 shows the share of residential heat demand in German municipalities that can be covered by the excess heat from biogas plants with the help of $\mathrm{DH}$. The calculation A.1 serves as a basis for the figure, and $\mathrm{DH}$ connections where the payback period is longer than 20 years were not taken into account. The figure shows that especially in the southern (Baden-Wuerttemberg and Bavaria) and northern federal states (Schleswig-Holstein, Mecklenburg-Western Pomerania, Lower Saxony, Saxony-Anhalt and Brandenburg), the most heat demand per municipality can be covered. In total, there is a potential in 3,591 $(32 \%)$ of the 11,400 German municipalities, in the other municipalities the value is $0 \%$. The mean value in the 3,591 municipalities is $12 \%$ and the $\mathrm{CO}_{2}$ emissions per capita are reduced 
by an average of $250 \mathrm{kgCO}_{2} / \mathrm{a}$. Some of the municipalities can cover almost all of their heat demand with $\mathrm{DH}$ from the biogas plant(s). More than $85 \%$ of the heat demand is met in 21 municipalities, while a maximum value of $98 \%$ is reached in the municipality of "Bresegard bei Eldena" (200 inhabitants) in Mecklenburg-Western Pomerania. In some municipalities, excess heat from biogas plants can therefore contribute to achieving energy autonomy. These results at the municipal level can be found in the online supplementary material.

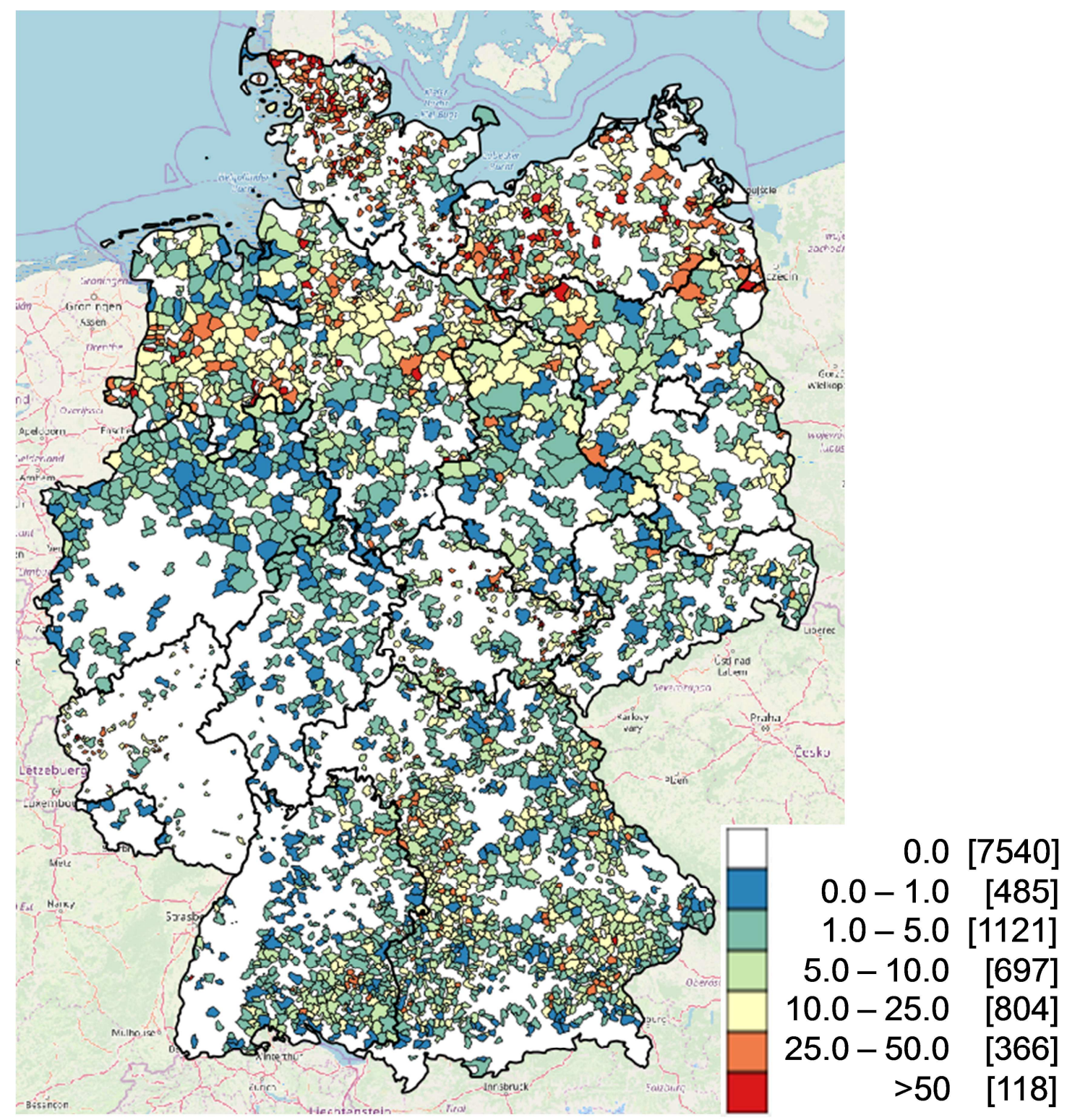

Figure 13: Share of heat demand that can be covered by $\mathrm{DH}$ from biogas in German municipalities. The numbers in brackets represent the number of municipalities to which the shares can be allocated. The background map is from OpenStreetMap contributors (2018).

\subsection{Critical appraisal of the methodology}

The sensitivity analysis considered the uncertainties in the parameters used, such as costs. However, the algorithm applied here also has some weaknesses that would not occur in the detailed planning of each individual biogas plant. This section first explains the weaknesses, which may lead to overestimating the calculated technical potential of $\mathrm{DH}$ by excess heat from biogas plants. Subsequently, the weaknesses that reduce the real technical potential are identified. Finally, the uncertainties relating to the method are discussed. 
First of all, some assumptions are made in the algorithm used here, which can lead to a moderate to severe underestimation of the costs. For example, the shortest route from the biogas plant to the settlements is always used for the DHPs. Here, however, the topology and other obstacles should be considered as in Nielsen (2014). Whilst data on surface topology is available in the form of Digital Elevation Models, it was not possible in this study to consider other obstacles. Given the objective of the study, to determine the overall technical potential for excess heat utilisation, this would also have been beyond the scope. In practice, however, a detailed DHN planning process would have to be carried out for individual municipalities.

In addition, the profiles for heat supply and demand were assumed. On the one hand, it is not certain that the biogas plants will actually be operated in the periods in which the heat demand in the settlements is highest (winter). On the other hand, the standard load profile $S L P_{H D}$ from Eq. 2 can only be accurately be applied in municipalities with several hundred households. In the smallest settlement area, there are only three households with a total of five inhabitants. However, the influence of this uncertainty is low, since in the calculations only $7 \%$ of the connected settlement areas have less than 100 households. Furthermore, the standard load profile was assumed to be equal for all settlements in Germany. In reality, differences between settlements from different regions could be found. In general, however, for this study the standard load profile should represent an appropriate estimation of the real load profiles in the settlements.

In some cases the costs are overestimated, however, as the following example illustrates. Figure 14 shows the DHN for using the excess heat from a biogas plant in the municipality of Cavertitz in Saxony. The problem lies in the fact that the algorithm iteratively selects the optimal connection in each step. The result is that the blue-coloured DHP furthest to the left is selected before the red coloured DHP furthest to the left. If the red DHP had been "built" first, there would have been a shorter distance to the settlement area in the bottom left, which is supplied by the blue DHP. This uncertainty has a low impact on costs, due to the fact that this phenomenon only occurs very rarely. In scenario A.1, for example, only $6 \%$ of $\mathrm{DH}$ connections start in settlement areas. Of this $6 \%$, only a few connections will show this fault, in Figure 14 it is only one connection of five.

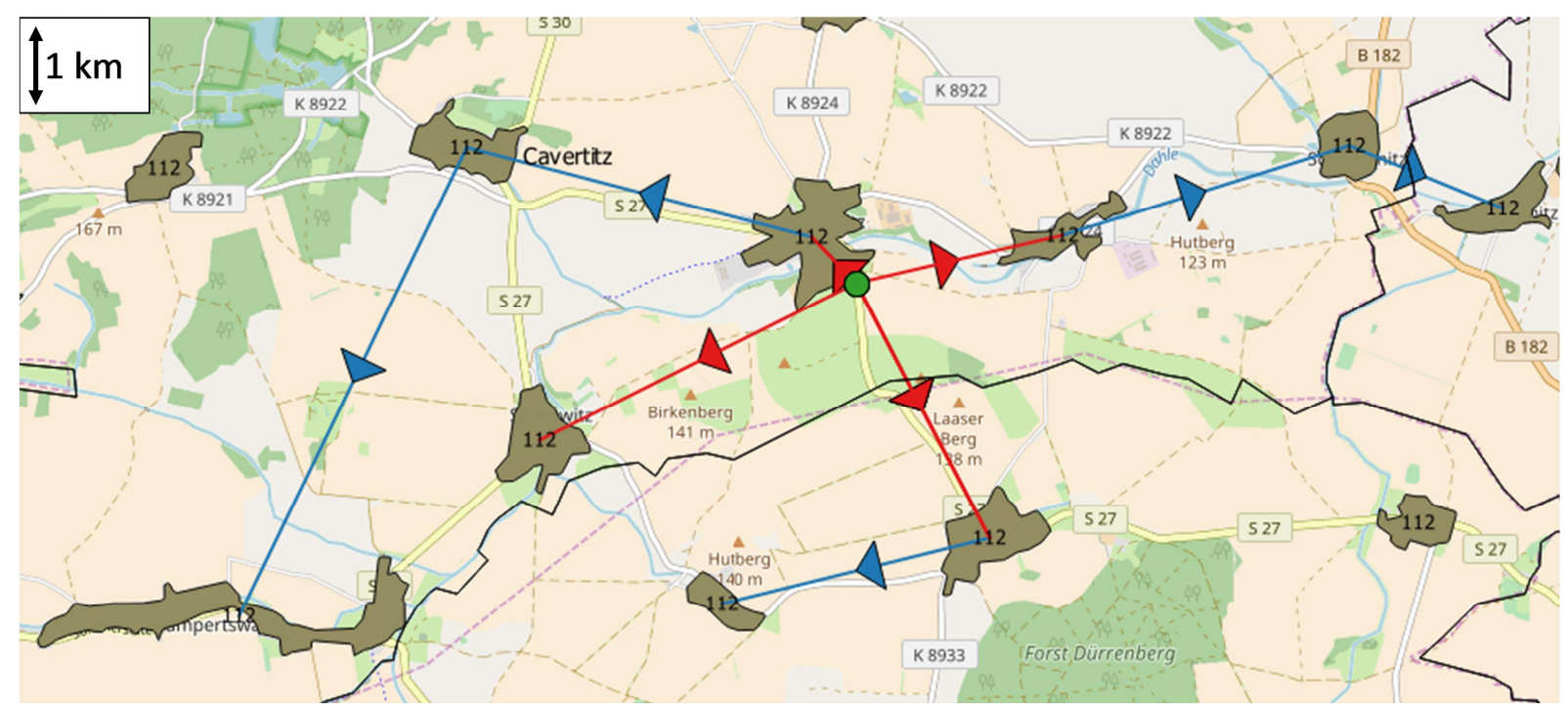

Figure 14: DHN for the utilisation of the excess heat from a biogas plant in the municipality of Cavertitz in Saxony. The background map is from OpenStreetMap contributors (2018). 
Figure 14 also shows that the selection of the area centroid for distance measurement overestimates the length of the DHPs from the biogas plants to the settlement areas in this case. Actually, only the distance to the border of the settlements should be measured here. However, this determination was not possible since the distance calculation is only possible with point coordinates. This could lead to a moderate increase in costs. For example, the settlement area at the bottom left of Figure 14 has a width of 4.2 kilometres. In extreme cases, the length of the DHPs could therefore be overestimated by around $2 \mathrm{~km}$.

Additionally, an existing $\mathrm{DH}$ supply can be deducted from the heating demand of the settlements, but no existing DHG can be taken into account due to a lack of data. If these data were available, the length of the DHPs to be built could be reduced, as they would no longer have to lead to the settlement, but only to the nearest connection point of the existing DHG. The impact on costs is estimated to be negligible, due to the limited number of existing district heating networks in Germany. In other countries, such as Iceland or Denmark, the costs for the use of waste heat from biogas plants could be considerably lower due to the significantly higher DHG share (Euroheat \& Power 2016).

A further overestimation of costs results from the fact that only residential areas are considered and not industrial or commercial areas. Some promising progress in this area has been made by the Pan-European Thermal Atlas (PETA) in the context of the Heat Roadmap Europe project ${ }^{4}$. Within the PETA urban areas are considered as "coherent urban areas", including industry and commercial sector, and existing DHNs are considered on a detailed level. However, at the time of carrying out this study, this data was not publicly available.

Figure 15 shows the municipality of Leutenbach in Baden-Württemberg. Blue surfaces are used here to represent the CLC areas. Red areas are individual buildings from Geofabrik (2018). The figure shows that the CLC data do not cover all existing settlement areas (cf. red circles in the Figure 15), as there is a minimum threshold for the size of an urban area to be differentiated in the CLC data $\left(0.05 \mathrm{~km}^{2}\right)$ and the data are from 2012 (so do not consider newer buildings). In the example shown in Figure 15, the excluded settlement areas are relatively small, so the implications for the results are likely to be only marginal.

\footnotetext{
${ }^{4}$ http://www.heatroadmap.eu/maps.php
} 


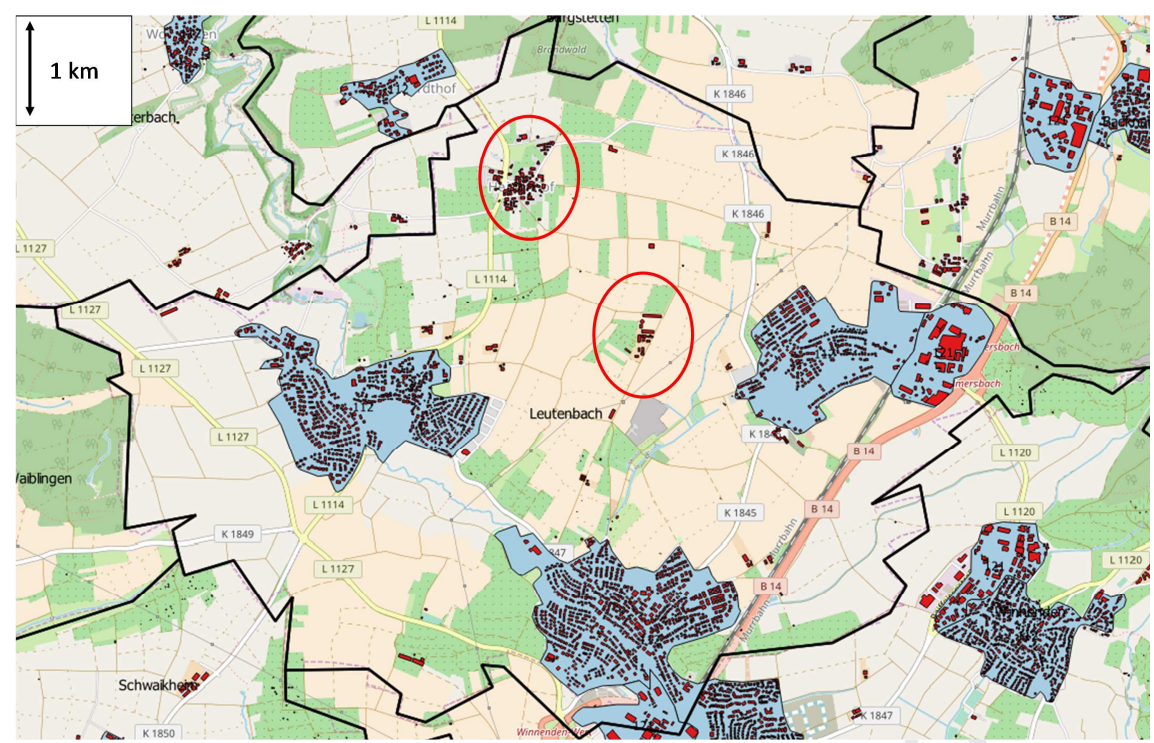

Figure 15: Settlement areas from the CLC data set and buildings in the municipality of Leutenbach in BadenWürttemberg (Geofabrik 2018). The background map is from OpenStreetMap contributors (2018).

A further uncertainty arises from the age of biogas plants. The age profile of the existing plants means that some of these plants will cease to benefit from the feed-in tariffs of the Renewable Energy Sources Act upon which they rely to be economic. After this time, their continued operation is uncertain. The plants should already have broken even after twenty years, as studies have shown payback periods in the region of 7-12 years depending on the substrate and the output (Balussou et al. 2011). Hence the plant may continue to operate, but the negative impact on the economics of losing the FITs could force the operators to seek other business models such as biomethane uprading and feed-in (cf. section A.1 in the appendix). In the absence of new business models, the plants might be forced to close, which would mean the excess heat considered here is no longer available. Instead, this study assumes constant cash flows over the 20 year lifetime of the $\mathrm{DH}$ project, which obviously neglects this issue. However, this study aimed to assess the current technical potential for excess heat use from biogas plants, and there are always future uncertainties associated with such analyses. Potential future business models for biogas plant operators in a post-EEG context could be the subject of a future contribution.

Finally and partly independently of the future development of the biogas sector, the dynamic of the surrounding energy system was not analysed in any detail in this study. In particular, the decarbonisation of the energy system means a shift away from fossil fuels towards renewable heat and electricity supply. The German government has ambitious climate targets in the context of the energy transition, including $50 \%$ renewable electricity consumption by 2030 and an $80 \%$ reduction in building primary energy demand by 2050 . Assuming these targets are met within this timeframe implies a deep insulation of existing buildings as well as shift towards gas-fired cogeneration (in the short term) and heat pumps (in the long term, cf. Merkel et al. 2016). Hence the $\mathrm{CO}_{2}$ intensity of existing heat supply would significantly reduce and similarly tend to decrease the potential impact of the results for $\mathrm{CO}_{2}$ abatement through district heating from biogas plants presented in this paper.

\section{Summary and conclusions}


This paper has analysed the current technical potential for utilising excess heat from biogas plants, in order to supply local settlements through district heating. Due to the high production of biogas, Germany was selected as the case study. Based on a survey of around 600 biogas plant operators, the fractions of excess heat from the cogeneration unit in these plants have been analysed. The analysis was carried out for the surveyed population as well as scaled up to the whole German biogas plant stock. A heuristic was developed to connect biogas plants (heat sources) with local settlements (sinks) in order to determine a least-cost district heating supply for residential buildings. Thereby two criteria were employed, namely the $\mathrm{CO}_{2}$ abatement costs and the payback period, which represent the macro- and microeconomic perspectives respectively.

Based on the survey, a mean fraction of $40 \%$ excess heat was determined, which is in agreement with other empirical studies. Extrapolating this fraction to the German biogas plant stock leads to technically feasible $\mathrm{CO}_{2}$ savings of around $2.5 \mathrm{MtCO}_{2} / \mathrm{a}$. Employing the criteria of $\mathrm{CO}_{2}$ abatement costs and payback period yields about $2 \mathrm{MtCO}_{2} / \mathrm{a}$ below $\mathrm{CO}_{2}$ abatement costs of $200 € / \mathrm{tCO}_{2}$ and 9 years respectively. These relatively high average costs are related to the typically low population density in rural regions where biogas plants are located. The potential $\mathrm{CO}_{2}$ savings represent about $0.25 \%$ of the total German $\mathrm{CO}_{2}$ emissions in 2016 or around $2.5 \%$ of all $\mathrm{CO}_{2}$ in residential buildings. If a threshold value of $80 € / \mathrm{tCO} 2$, to reflect the German government's suggested external cost of carbon, is employed, the carbon reduction potential is about $0.5 \mathrm{MtCO}_{2}$. Similarly, a threshold for the expected payback period of 5 years, to reflect an investor's point of view yields potential savings of $0.75 \mathrm{MtCO}_{2}$. These potentials are concentrated in around 3,500 municipalities, where district heating from biogas plants could reduce $\mathrm{CO}_{2}$ emissions per capita by an average of $250 \mathrm{kgCO}_{2} / \mathrm{a}$ and cover $12 \%$ of the total residential heating demand. In some of these municipalities, large proportions of their heating demand could be economically met (according to the criteria employed here) by this excess heat, hence assisting in the transition to more decentralised autonomous energy systems. On the other hand, if the current price of $\mathrm{CO}_{2}$ in the EU Emissions Trading System of about $7 € / \mathrm{tCO}_{2}$ is taken as a benchmark, the economic fraction of this technical potential saving reduces to $0 \mathrm{tCO}_{2}$. Although these results are relatively modest in the overall context of decarbonising the energy system, this study does provide a quantitative basis for decision makers, researchers and energy planners. The detailed results provided as supplementary material should offer useful insights for local planners and authorities when considering the sustainable energy options at their disposal.

The developed method was applied to a German case study, but could be equally relevant for other countries with high biogas production. Some of these countries (e.g. Denmark) have a significantly more widespread district heating network than Germany. Thus, the use of biogas excess heat could lead to similar or even better results for these countries than in the case study for Germany. Apart from a methodology that can be transferred to any country with similar data availability, the present study therefore demonstrates that the use of excess heat in biogas plants can be one contribution towards a global energy system decarbonisation.

The employed methodology, whilst adequate for a national estimation of the technical potential and associated costs, has several uncertainties. Most importantly, the shortest birds-eye route from the biogas plant to the centroid of the settlement is used as the required 
distance for the pipeline. Whilst a good estimate for the order of magnitude, this obviously leads to over- and underestimates of the required district heating pipeline length, and therefore the costs. In addition, the developed heuristic does not (necessarily) determine the optimum allocation of heat sources to heat sinks, and may also therefore overestimate the costs. Finally, the focus on residential buildings and the rough consideration of existing district heating supply (but not infrastructure) add additional uncertainties. All of these aspects remain areas for future work.

\section{Acknowledgements}

The authors gratefully acknowledge the financial support of the $\mathrm{PhD}$ College "Energy and Resource Efficiency" (ENRES), from the Federal State of Baden-Wuerttemberg, for funding the first author's PhD studentship. The authors also thank five anonymous reviewers, who provided valuable comments on earlier versions of this manuscript. 


\section{References}

Agentur für Erneuerbare Energien (2013): Potenzialatlas: Bioenergie in den Bundesländern. Available online at https://www.unendlich-vielenergie.de/mediathek/broschueren/potenzialatlas-bioenergie-in-den-bundeslaendern, checked on 10/29/2018.

American Association for Public Opinion Research (AAPOR) (2015): Standard Definitions. Final Dispositions of Case Codes and Outcome Rates for Surveys. Available online at https://www.aapor.org/AAPOR_Main/media/publications/StandardDefinitions2015_8theditionwithchanges_April2015_logo.pdf, checked on 2/22/2018.

Arbeitsgemeinschaft QM Fernwärme (2017): Planungshandbuch Fernwärme.

Balussou, D., Kleyböcker, A., McKenna, R., Möst, D., Fichtner, W. (2011): An economic analysis of three operational co-digestion biogas plants in Germany, Waste and Biomass Val., 3, 1, pp. 23-41.

BDEW Bundesverband der Energie- und Wasserwirtschaft e.V (2018): BDEWStrompreisanalyse Mai 2017. Berlin.

Bidart, C. (2013): A Techno-economic Assessment of the Generation and Usage of Biogenic Gases in Chile as a Substitute of Natural Gas, Dissertation at the Karlsruhe Institute for Technology (KIT), Karlsruhe, https://publikationen.bibliothek.kit.edu/1000038622.

BMJV (2018): Gesetz für die Erhaltung, die Modernisierung und den Ausbau der KraftWärme-Kopplung (Kraft-Wärme-Kopplungsgesetz - KWKG). Edited by Bundesministeriums der Justiz und für Verbraucherschutz. Available online at https://www.destatis.de/DE/Methoden/Rechtsgrundlagen/Statistikbereiche/Inhalte/1058_KW KG.pdf?_blob=publicationFile, checked on 3/2/2018.

Bordin, Chiara; Gordini, Angelo; Vigo, Daniele (2016): An optimization approach for district heating strategic network design. In European Journal of Operational Research 252 (1), pp. 296-307. DOI: 10.1016/j.ejor.2015.12.049.

Brueckner S, Miró L, Cabeza LF, Pehnt M, Laevemann E. (2014): Methods to estimate the industrial waste heat potential of regions - A categorization and literature review. Renewable and Sustainable Energy Reviews. 2014;38:164-71.

Bundesnetzagentur (2017a): Hintergrundpapier Ergebnisse der Ausschreibung für Biomasse vom 1. September 2017. Available online at https://www.bundesnetzagentur.de/SharedDocs/Downloads/DE/Sachgebiete/Energie/Untern ehmen_Institutionen/Ausschreibungen_2017/Biomasse17/Hintergrundpapier_0109_2017.pdf ;jsessionid=1378DD2EAA88519EF6C80AB26B404C85?_blob=publicationFile\&v=6.

Bundesnetzagentur (2017b): Monitoring report. Available online at https://www.bundesnetzagentur.de/SharedDocs/Downloads/EN/Areas/ElectricityGas/Collecti onCompanySpecificData/Monitoring/MonitoringReport2017.pdf;jsessionid=71D2FEC153FC2 E747ABAB81ED01A05F8?_blob=publicationFile\&v=2, checked on 10/29/2018.

Bundesnetzagentur (2018): EEG-Anlagenstammdaten (außer PV-Gebäudeanlagen). Available online at https://www.bundesnetzagentur.de/DE/Sachgebiete/ElektrizitaetundGas/Unternehmen_Instit 
utionen/ErneuerbareEnergien/ZahlenDatenInformationen/EEG_Registerdaten/EEG_Register daten_node.html, checked on 3/4/2018.

Bühler F, Petrović S, Karlsson K, Elmegaard B. (2017): Industrial excess heat for district heating in Denmark. Applied Energy. 2017;205:991-1001.

Burgess, P. J., Casado, M. R., Gavu, J., Mead, A., Cockerill, T., Lord, R., Van der Horst, D., Howard, D. C. (2012): A framework for reviewing the trade-offs between, renewable energy, food, feed and wood production at a local level. In Renewable and sustainable energy reviews, 16(1), 129-142.

C.A.R.M.E.N. e.V (2012): Nahwärmenetze und Bioenergieanlagen. Ein Beitrag zur effizienten Wärmenutzung und zum Klimaschutz. Available online at https://www.carmenev.de/files/festbrennstoffe/merkblatt_Nahwaermenetz_carmen_ev.pdf, checked on 2/16/2018.

Casisi, M.; Pinamonti, P.; Reini, M. (2009): Optimal lay-out and operation of combined heat \& power (CHP) distributed generation systems. In Energy 34 (12), pp. 2175-2183. DOI: 10.1016/j.energy.2008.10.019.

Chinese, D. (2008): Optimal size and layout planning for district heating and cooling networks with distributed generation options. In International Journal of Energy Sector Management 2 (3), pp. 385-419. DOI: 10.1108/17506220810892946.

Clearingstelle EEG (2006): EEG 2004. Available online at https://www.clearingstelle-eegkwkg.de/eeg2004, checked on 3/2/2018

Clearingstelle EEG (2009): EEG 2009. Available online at https://www.clearingstelle-eegkwkg.de/eeg2009, checked on 2/26/2018.

Clearingstelle EEG (2012): EEG 2012. Available online at https://www.clearingstelle-eegkwkg.de/eeg2012, checked on 2/26/2018.

Coss, Stefano; Verda, Vittorio; Le-Corre, Oliver (2018): Multi-objective optimization of district heating network model and assessment of demand side measures using the load deviation index. In Journal of Cleaner Production 182, pp. 338-351. DOI:

10.1016/j.jclepro.2018.02.083.

Dahlin, Johannes; Herbes, Carsten; Nelles, Michael (2015): Biogas digestate marketing. Qualitative insights into the supply side. In Resources, Conservation and Recycling 104, pp. 152-161. DOI: 10.1016/j.resconrec.2015.08.013.

Dahlin, Johannes; Halbherr, Verena; Kurz, Peter; Nelles, Michael; Herbes, Carsten (2016): Marketing Green Fertilizers. Insights into Consumer Preferences. In Sustainability 8 (11), p. 1169. DOI: $10.3390 /$ su8111169.

Dahlin, Johannes; Nelles, Michael; Herbes, Carsten (2017): Biogas digestate management. Evaluating the attitudes and perceptions of German gardeners towards digestate-based soil amendments. In Resources, Conservation and Recycling 118, pp. 27-38. DOI:

10.1016/j.resconrec.2016.11.020. 
Dahlin, Johannes; Beuthner, Christoph; Halbherr, Verena; Kurz, Peter; Nelles, Michael; Herbes, Carsten (2018): Sustainable Compost and Potting Soil Marketing. Private Gardener Preferences. In Journal of Cleaner Production. DOI: 10.1016/j.jclepro.2018.10.068.

DBFZ (2015): Stromerzeugung aus Biomasse. Available online at https://www.dbfz.de/fileadmin/eeg_monitoring/berichte/01_Monitoring_ZB_Mai_2015.pdf, checked on 2/19/2018.

dena (2016): Branchenbarometer Biomethan: Daten, Fakten und Trends zu Biomethan, dena, Berlin.

DIW Berlin; EEFA (2017): Auswertungstabellen zur Energiebilanz Deutschland. 1990 bis 2016. Edited by AGEB AG Energiebilanzen e.V. Available online at https://www.agenergiebilanzen.de/, checked on 1/4/2018.

Dobersek, D.; Goricanec, D. (2009): Optimisation of tree path pipe network with nonlinear optimisation method. In Applied Thermal Engineering 29 (8-9), pp. 1584-1591. DOI: 10.1016/j.applthermaleng.2008.07.017.

EEA (1995): CORINE Land cover - Part 2: Nomenclature. Edited by European Environment Agency. Available online at https://www.eea.europa.eu/publications/COR0-part2, checked on $11 / 28 / 2017$.

EEA (2016): CORINE Land Cover 2012 seamless vector data. Edited by European Environment Agency. Available online at https://www.eea.europa.eu/downloads/5c537b70226944b8bfe7bdc9470100ff/1488296244/cl c-2012-vector.pdf, checked on 11/28/2017.

EEA (2017): CORINE Land Cover (CLC). Edited by European Environment Agency. Available online at https://land.copernicus.eu/user-corner/publications/clc-flyer/view, checked on $3 / 1 / 2018$.

EEA (2018): Land cover country fact sheets 2012. Edited by European Environment Agency.Online verfügbar unter https://www.eea.europa.eu/themes/landuse/land-covercountry-fact-sheets?b_start:int=0, zuletzt geprüft am 18.10.2018.

Engel, T. (2015): Die Daten Der Energymap Zum Download. Edited by Deutsche Gesellschaft für Sonnenenergie e.V. (DGS). Available online at http://www.energymap.info/download.html, checked on 11/28/2017.

Ertem, Funda Cansu; Martínez-Blanco, Julia; Finkbeiner, Matthias; Neubauer, Peter; Junne, Stefan (2016): Life cycle assessment of flexibly fed biogas processes for an improved demand-oriented biogas supply. In Bioresource technology 219, pp. 536-544. DOI: 10.1016/j.biortech.2016.07.123.

Ertem, Funda Cansu; Neubauer, Peter; Junne, Stefan (2017): Environmental life cycle assessment of biogas production from marine macroalgal feedstock for the substitution of energy crops. In Journal of Cleaner Production 140, pp. 977-985. DOI:

10.1016/j.jclepro.2016.08.041.

Euroheat \& Power (2016): Top District Heating Countries - Euroheat \& Power 2015 Survey Analysis. Available online at https://www.euroheat.org/news/district-energy-in-the-news/topdistrict-heating-countries-euroheat-power-2015-survey-analysis/, checked on 5/14/2019. 
Euroheat \& Power (2017): District Energy in Germany. Available online at https://www.euroheat.org/knowledge-centre/district-energy-germany/, checked on 9/27/2018.

European Biogas Association (2016): 17,358 biogas plants in Europe (31/12/2015). Available online at http://european-biogas.eu/wp-content/uploads/2017/01/Graph-1-Number-of-biogasplants.png, checked on 10/29/2018.

Fachagentur Nachwachsende Rohstoffe (FNR) (2017): Basisdaten Bioenergie Deutschland 2017. Available online at

http://www.fnr.de/fileadmin/allgemein/pdf/broschueren/Basisdaten_Bioenergie_2018.pdf, checked on 10/29/2018.

Fachagentur Nachwachsende Rohstoffe (FNR) (2015): Biomassepotenziale von Rest- und Abfallstoffen - Status Quo in Deutschland. Available online at https://mediathek.fnr.de/band36-biomassepotenziale-von-rest-und-abfallstoffen.html, checked on 10/29/2018.

Fang H, Xia J, Zhu K, Su Y, Jiang Y. (2013): Industrial waste heat utilisation for low temperature district heating. Energy Policy. 2013;62:236-46.

Fang H, Xia J, Jiang Y. (2015): Key issues and solutions in a district heating system using low grade industrial waste heat. Energy. 2015;86:589-602.

Fazlollahi, Samira; Girardin, Luc; Maréchal, François (2014): Clustering Urban Areas for Optimizing the Design and the Operation of District Energy Systems. In : 24th European Symposium on Computer Aided Process Engineering, vol. 33: Elsevier (Computer Aided Chemical Engineering), pp. 1291-1296.

Fraunhofer IEE (2018): Vorbereitung und Begleitung bei der Erstellung eines

Erfahrungsberichts gemäß §97 Erneuerbare-Energien-Gesetz. Teilvorhaben II a: Biomasse.

Zwischenbericht. Available online at https://www.erneuerbare-

energien.de/EE/Redaktion/DE/Downloads/bmwi_de/bericht-eeg-2-

biomasse.pdf?_blob=publicationFile\&v=8, checked on 10/29/2018.

Fraunhofer UMSICHT, Leitfaden Nahwärme, Fraunhofer IRB Verlag, Stuttgart, 1998. doi:10.24406/UMSICHT-PX-52182.

Geofabrik (2018): Regierungsbezirk Stuttgart. Available online at http://download.geofabrik.de/europe/germany/baden-wuerttemberg/stuttgart-regbez.html, checked on 2/15/2018.

German Biogas Association (2017): Biogas market data in Germany 2016/20176/2017.

Available online at https://www.biogas.org/edcom/webfvb.nsf/id/DE_Branchenzahlen/\$file/1710-13_Biogasindustryfigures-2016-2017.pdf.

Good, Jügern (2004): Planungshandbuch. Straubing: C.A.R.M.E.N. e.V (Schriftenreihe QM Holzheizwerke, 4).

Guelpa, Elisa; Mutani, Guglielmina; Todeschi, Valeria; Verda, Vittorio (2018): Reduction of $\mathrm{CO} 2$ emissions in urban areas through optimal expansion of existing district heating networks. In Journal of Cleaner Production 204, pp. 117-129. DOI:

10.1016/j.jclepro.2018.08.272. 
Hahn, Henning; Ganagin, Waldemar; Hartmann, Kilian; Wachendorf, Michael (2014): Cost analysis of concepts for a demand oriented biogas supply for flexible power generation. In Bioresource technology 170, pp. 211-220. DOI: 10.1016/j.biortech.2014.07.085.

Herbes, Carsten; Jirka, Eva; Braun, Jan Philipp; Pukall, Klaus (2014): Der gesellschaftliche Diskurs um den ,,Maisdeckel“ vor und nach der Novelle des Erneuerbare-Energien-Gesetzes (EEG) 2012The Social Discourse on the „Maize Cap“ before and after the 2012 Amendment of the German Renewable Energies Act (EEG). In GAIA - Ecological Perspectives for Science and Society 23 (2), pp. 100-108. DOI: 10.14512/gaia.23.2.7.

Herbes, Carsten (2015): Marketing für Biomethan. In Christian Friege, Carsten Herbes (Eds.): Marketing Erneuerbarer energien. Grundlagen, Geschäftsmodelle, Fallbeispiele. Wiesbaden: Springer Gabler, pp. 183-201.

Herbes, C., Halbherr, V. (2017): Stärkere Wärmenutzung in Biogasanlagen kann sich lohnen, Biogas Journal, 1, 2017, 68-71.

Herbes, Carsten; Halbherr, Verena; Braun, Lorenz (2018a): Factors influencing prices for heat from biogas plants. In Applied Energy 221, pp. 308-318. DOI:

10.1016/j.apenergy.2018.03.188.

Herbes, Carsten; Brummer, Vasco; Roth, Sandra; Röhl, Markus (2018b): Using aquatic plant biomass from de-weeding in biogas processes - an economically viable option? In Energ Sustain Soc 8 (1), p. 175. DOI: 10.1186/s13705-018-0163-2.

Hochloff, Patrick; Braun, Martin (2014): Optimizing biogas plants with excess power unit and storage capacity in electricity and control reserve markets. In Biomass and Bioenergy 65, pp. 125-135. DOI: 10.1016/j.biombioe.2013.12.012.

Jenssen, T., König, A., Eltrop, L. (2014): Bioenergy villages in Germany: Bringing a low carbon energy supply for rural areas into practice. In Renewable Energy, 61, 74-80.

Karner, Katharina; Theissing, Matthias; Kienberger, Thomas (2016): Energy efficiency for industries through synergies with urban areas. In: Journal of Cleaner Production 119, S. 167-177. DOI: 10.1016/j.jclepro.2016.02.010.

Karner, Katharina; McKenna, Russell; Klobasa, Marian; Kienberger, Thomas (2018):

Industrial excess heat recovery in industry-city networks. A technical, environmental and economic assessment of heat flexibility. In Journal of Cleaner Production 193, pp. 771-783. DOI: 10.1016/j.jclepro.2018.05.045.

Karschin, Ingo; Geldermann, Jutta (2015): Efficient cogeneration and district heating systems in bioenergy villages. An optimization approach. In Journal of Cleaner Production 104, pp. 305-314. DOI: 10.1016/j.jclepro.2015.03.086.

Klaus Novy Institut e.V. \& trend:research (2011) „Marktakteure: Erneuerbare-EnergienAnlagen in der Stromerzeugung“, [Market actors: renewable energy plants in electricity generation], Köln.

Klein, C.; Rozanski, K.; Gailfuß, M.; Kukuk, J.; Beck, T. (2014): BHKW-Kenndaten 2014/15. Edited by ASUE Arbeitsgemeinschaft für sparsamen und umweltfreundlichen Energieverbrauch e.V. Berlin. Available online at 
http://www.asue.de/blockheizkraftwerke/broschueren/05_10_14_bhkw-kenndaten_2014-15, checked on 2/13/2018.

Köppel, W.; Schreck, H.; Lubenau, U.; Erler, R. (2014): Abschlussbericht. Monitoring Biogas II. Edited by DVGW Deutscher Verein des Gas- und Wasserfaches e. V. Available online at https://www.dvgw.de/index.php?elD=dumpFile\&t=f\&f=2167\&token=7ec5a7b7c61b4d21e7f9f a6fd694767d0dece9b5, checked on 3/2/2018.

Landesamt für Statistik Niedersachsen (2014): Gebäude- und Wohnungsbestand in Deutschland. Erste Ergebnisse der Gebäude- und Wohnungszählung 2011. Edited by Statistische Ämter des Bundes und der Länder. Hannover. Available online at https://www.statistik.rlp.de/fileadmin/dokumente/gemeinschaftsveroeff/zen/Zensus_GWZ_20 14.pdf, checked on 11/28/2017.

Lauer, Markus; Thrän, Daniela (2017): Biogas plants and surplus generation: Cost driver or reducer in the future German electricity system? In Energy Policy 109, pp. 324-336. DOI: 10.1016/j.enpol.2017.07.016.

Lauer, Markus; Dotzauer, Martin; Hennig, Christiane; Lehmann, Monique; Nebel, Eva; Postel, Jan et al. (2017): Flexible power generation scenarios for biogas plants operated in Germany. Impacts on economic viability and GHG emissions. In Int. J. Energy Res. 41 (1), pp. 63-80. DOI: 10.1002/er.3592.

Lenk, M.; Boumann, J.; Sippel, T. (2017a): CORINE Land Cover 10 ha. Available online at http://www.geodatenzentrum.de/geodaten/gdz_rahmen.gdz_div?gdz_spr=deu\&gdz_akt_zeil e=5\&gdz_anz_zeile=1\&gdz_unt_zeile=22\&gdz_user_id=0, checked on 11/28/2017.

Lenk, M.; Boumann, J.; Sippel, T. (2017b): Verwaltungsgebiete 1:250 000 - Stand 01.01.2017. Available online at

http://www.geodatenzentrum.de/geodaten/gdz_rahmen.gdz_div?gdz_spr=deu\&gdz_akt_zeil e=5\&gdz_anz_zeile=1\&gdz_unt_zeile=14\&gdz_user_id=0, checked on 12/18/2017.

LfU (2016): Berechnung der CO2-Emissionen. Edited by Bayrisches Landesamt für Umwelt. Available online at https://www.umweltpakt.bayern.de/energie_klima/fachwissen/217/berechnung-co2emissionen, updated on 9/21/2016, checked on 1/9/2018.

Liebetrau, Jan; Sträuber, Heike; Kretzschmar, Jörg; Denysenko, Velina; Nelles, Michael (2017): Anaerobic Digestion. In Advances in biochemical engineering/biotechnology. DOI: 10.1007/10_2016_67.

Markard, Jochen; Wirth, Steffen; Truffer, Bernhard (2016): Institutional dynamics and technology legitimacy - A framework and a case study on biogas technology. In Research Policy 45 (1), pp. 330-344. DOI: 10.1016/j.respol.2015.10.009.

Maroušek, Josef (2014): Significant breakthrough in biochar cost reduction. In Clean Techn Environ Policy 16 (8), pp. 1821-1825. DOI: 10.1007/s10098-014-0730-y.

Maroušek, Josef; Stehel, Vojtěch; Vochozka, Marek; Maroušková, Anna; Kolář, Ladislav (2018): Postponing of the intracellular disintegration step improves efficiency of phytomass processing. In Journal of Cleaner Production 199, pp. 173-176. DOI:

10.1016/j.jclepro.2018.07.183. 
Marquant, Julien F.; Bollinger, L. Andrew; Evins, Ralph; Carmeliet, Jan (2018): A new combined clustering method to Analyse the potential of district heating networks at largescale. In Energy 156, pp. 73-83. DOI: 10.1016/j.energy.2018.05.027.

Marty, Fabien; Serra, Sylvain; Sochard, Sabine; Reneaume, Jean-Michel (2018):

Simultaneous optimization of the District Heating Network topology and the Organic Rankine Cycle sizing of a geothermal plant. In Energy. DOI: 10.1016/j.energy.2018.05.110.

McKenna, R. C., Norman, J. B. (2010): Spatial modelling of industrial heat loads and recovery potentials in the UK, Energy Policy, 38, pp.5878-5891, doi:10.1016/j.enpol.2010.05.042.

McKenna, Russell; Merkel, Erik; Fehrenbach, Daniel; Mehne, Stephanie; Fichtner, Wolf (2013): Energy efficiency in the German residential sector. A bottom-up building-stockmodel-based analysis in the context of energy-political targets. In Building and Environment 62, pp. 77-88. DOI: 10.1016/j.buildenv.2013.01.002.

McKenna, R. (2018): The double-edged sword of decentralized energy autonomy, Energy Policy, Volume 113, February 2018, Pages 747-750, https://doi.org/10.1016/j.enpol.2017.11.033

Mergner et al. (2013): National policy enforcement for heat use from biogas in Austria, Coratia, Czech Republic, Denmark, Germany, Italy, Latvia, Poland and Romania, Biogas Heat Project Deliverable 2.4, Project IEE/11/025.

Merkel, E., McKenna, R., Fehrenbach, D., Fichtner, W. (2016): A model-based assessment of climate and energy targets for the German residential heat system, Journal of Cleaner Production, 142, 4, 3151-3173, http://dx.doi.org/10.1016/j.jclepro.2016.10.153.

Microsoft (2018): Bing Maps. Available online at https://www.bing.com/maps/, checked on 2/22/2018.

Miró L, Brückner S, Cabeza LF (2015): Mapping and discussing Industrial Waste Heat (IWH) potentials for different countries. Renewable and Sustainable Energy Reviews. 2015;51:84755 .

Miró L, Brueckner S, McKenna R, Cabeza LF (2016): Methodologies to estimate industrial waste heat potential by transferring key figures: A case study for Spain. Applied Energy. 2016;169:866-73.

Müller, M. O., Stämpfli, A., Dold, U., Hammer, T. (2011): Energy Autarky: A conceptual framework for sustainable regional development, Energy Policy 39, 5800-5810.

Nielsen, Steffen (2014): A geographic method for high resolution spatial heat planning. In Energy 67, pp. 351-362. DOI: 10.1016/j.energy.2013.12.011.

Niesner, J., Jecha, D., Stehlik, P. (2013): Biogas Upgrading Technologies: State of Art Review in European Region, Chemical Engineering Transactions, 35, 517-522.

Nykvist, B., Nilsson, M. (2015): Rapidly falling costs of battery packs for electric vehicles, Nature Climate Change Letters, 5, 329-332, DOI: 10.1038/NCLIMATE2564

OpenStreetMap contributors (2018): OpenStreetMap. Available online at https://www.openstreetmap.org/\#map=5/51.330/10.453, checked on 1/29/2018. 
Pablo-Romero, María del P.; Sánchez-Braza, Antonio; Salvador-Ponce, Jesús; SánchezLabrador, Natalia (2017): An overview of feed-in tariffs, premiums and tenders to promote electricity from biogas in the EU-28. In Renewable and Sustainable Energy Reviews 73, pp. 1366-1379. DOI: 10.1016/j.rser.2017.01.132.

Persson, Urban; Werner, Sven (2011): Heat distribution and the future competitiveness of district heating. In Applied Energy 88 (3), pp. 568-576. DOI:

10.1016/j.apenergy.2010.09.020.

Persson U, Möller B, Werner S (2014): Heat Roadmap Europe: Identifying strategic heat synergy regions. Energy Policy. 2014;74:-81.

Pfnür, A.; Winiewska, B.; Mailch, B.; Qschatz, B. (2016): Dezentrale vs. zentrale Wärmeversorgung im deutschen Wärmemarkt. Vergleichende Studie aus energetischer und ökonomischer Sicht. Darmstadt. Available online at http://www.bdh-

koeln.de/fileadmin/user_upload/pressemitteilungen_pdf/studie_dezentrale_vs_zentrale_waer meversorgung.pdf, checked on 2/16/2018.

Pöschl, Martina; Ward, Shane; Owende, Philip (2010): Evaluation of energy efficiency of various biogas production and utilization pathways. In Applied Energy 87 (11), pp. 33053321. DOI: 10.1016/j.apenergy.2010.05.011.

Purkus, Alexandra; Gawel, Erik; Szarka, Nora; Lauer, Markus; Lenz, Volker; Ortwein, Andreas et al. (2018): Contributions of flexible power generation from biomass to a secure and cost-effective electricity supply-a review of potentials, incentives and obstacles in Germany. In Energ Sustain Soc 8 (1), p. 151. DOI: 10.1186/s13705-018-0157-0.

Rae, Callum; Bradley, Fiona (2012): Energy autonomy in sustainable communities - A review of key issues. In: Renewable and Sustainable Energy Reviews 16, S. 6497-6506.

Rutz, Dominik; Güntert, David (2012): Biogas Checklist for Administrative Bodies. In WIP_ Renewable Energies.

Rutz, D.; Mergner, R.; Janssen, R. (2015): Sustainable heat use of biogas plants. A handbook. 2nd edition. Munich, Germany: WIP Renewable Energies.

Scarlat, Nicolae; Dallemand, Jean-François; Fahl, Fernando (2018): Biogas. Developments and perspectives in Europe. In Renewable Energy 129, pp. 457-472. DOI:

10.1016/j.renene.2018.03.006.

Schwermer, S. (2012): Ökonomische Bewertung von Umweltschäden.

METHODENKONVENTION 2.0 ZUR SCHÄTZUNG VON UMWELTKOSTEN. Edited by Umweltbundesamt. Available online at https://www.umweltbundesamt.de/sites/default/files/medien/378/publikationen/uba_methode nkonvention_2.0_-_2012_gesamt.pdf, checked on 2/19/2018.

Schmidt, J., Schönhart, M., Biberacher, M., Guggenberger, T., Hausl, S., Kalt, G., Leduc, s., Schardinger, I., Schmid, E. (2012): Regional energy autarky: Potentials, costs and consequences for an Austrian region. In Energy Policy, 47, 211-221.

Soltero, V. M.; Chacartegui, R.; Ortiz, C.; Velázquez, R. (2018): Potential of biomass district heating systems in rural areas. In Energy 156, pp. 132-143. DOI:

10.1016/j.energy.2018.05.051. 
Statens Planverk (1985): Heat supply and city planning, Rapport 71, Stockholm

Statista (2018a): Gewerbe- und Industriestrompreise in Deutschland bis 2017. Available online at https://de.statista.com/statistik/daten/studie/154902/umfrage/strompreise-fuerindustrie-und-gewerbe-seit-2006/, checked on 02/05/2017.

Statista (2018b): Endenergieverbrauch der privaten Haushalte für Wohnen in Deutschland nach Anwendungsbereich im Jahresvergleich 2005 und 2015 (in Terawattstunden). Available online at https://de.statista.com/statistik/daten/studie/165364/umfrage/energieverbrauch-derprivaten-haushalte-fuer-wohnen-2000-und-2009/, checked on 1/4/2018.

Statistische Ämter des Bundes und der Länder (2011): Gebäude mit Wohnraum und Wohnungen nach Gebäudearten - Stichtag 09.05.2011. Available online at https://www.regionalstatistik.de/genesis/online/data;jsessionid=5D5DCB0C0C6EDCC42E561 52EFF2DA8B4.reg2?operation=abruftabelleAbrufen\&selectionname=31211-01-015\&levelindex=1\&levelid=1513613620454\&index=2, checked on 12/18/2017.

Statistisches Bundesamt (2015a): Fortschreibung auf Basis GWZ 2011 Wohngebäude- und Wohnungsbestand - Stichtag 31.12. - regionale Tiefe: Gemeinden, Samt-

Nerbandsgemeinden. Available online at https://www.regionalstatistik.de/genesis/online/data;jsessionid=E0E1257886684D86F22411 D184342C44.reg2?operation=abruftabelleAbrufen\&selectionname=31231-02-015\&levelindex $=1$ \&levelid=1511862729847\&index $=5$, checked on 11/28/2017.

Statistisches Bundesamt (2015b): Zensus 2011. Methoden und Verfahren. Edited by Statistische Ämter des Bundes und der Länder. Wiesbaden. Available online at https://www.zensus2011.de/SharedDocs/Downloads/DE/Publikationen/Aufsaetze_Archiv/201 5_06_MethodenUndVerfahren.pdf? blob=publicationFile\&v=6, checked on 11/28/2017.

Statistisches Bundesamt (2016a): Bauen und Wohnen. Mikrozensus - Zusatzerhebung 2014 Bestand und Struktur der Wohneinheiten Wohnsituation der Haushalte. Wiesbaden.

Available online at

https://www.destatis.de/DE/Publikationen/Thematisch/EinkommenKonsumLebensbedingung en/Wohnen/WohnsituationHaushalte2055001149004.pdf;jsessionid=1970E8F571F3A560CA 79DE823C7889CF.InternetLive1?_blob=publicationFile, checked on 1/9/2018.

Statistisches Bundesamt (2016b): Datenangebot zum Zensusatlas - Klassifizierte Ergebnisse. Ergebnisse des Zensus am 9. Mai 2011 pro km². Edited by Statistische Ämter des Bundes und der Länder. Wiesbaden. Available online at https://www.opengeodata.nrw.de/produkte/bevoelkerung/zensus2011/ergebnisse_1kmgitter/Datensatzbeschreibung_klassierte_Werte_1km-Gitter.pdf, checked on 11/28/2017.

Statistisches Bundesamt (2017a): Bestand an Wohnungen und Wohngebäuden Bauabgang von Wohnungen und Wohngebäuden - Lange Reihen ab 1969 - 2016. Available online at https://www.destatis.de/DE/Publikationen/Thematisch/Bauen/Wohnsituation/Fortschreibung WohnungsbestandPDF_5312301.pdf?_blob=publicationFile, checked on 12/18/2017.

Statistisches Bundesamt (2017b): Bevölkerungsstand. Available online at https://www.destatis.de/DE/ZahlenFakten/GesellschaftStaat/Bevoelkerung/Bevoelkerungssta nd/Tabellen_/rbev03.html, checked on 12/18/2017. 
Statistisches Bundesamt (2017c): Gemeindeverzeichnis - Gebietsstand: 30.06.2017 (2. Quartal). Alle politisch selbständigen Gemeinden (mit Gemeindeverband) in Deutschland nach Fläche, Bevölkerung (auf Grundlage des Zensus 2011), Bevölkerungsdichte und der Postleitzahl des Verwaltungssitzes der Gemeinde. Edited by Statistische Ämter des Bundes und der Länder. Wiesbaden. Available online at https://www.destatis.de/DE/ZahlenFakten/LaenderRegionen/Regionales/Gemeindeverzeichn is/Administrativ/Archiv/GVAuszugQ/AuszugGV2QAktuell.html, checked on 9/7/2017.

SWB (2014): Technische Anschlussbestimmungen für den Anschluss an das Fernwärmenetz der Stadtwerke Bönnigheim. Edited by Stadtwerke Bönnigheim. Available online at http://www.stadtwerke-boennigheim.de/resources/ecics_42.pdf, checked on $3 / 1 / 2018$.

Theissing, M. (2012): CO2 - Emissionen und Primärenergiefaktor der Fernwärme in Österreich, in: Fernwärmetage 2012, Wels.

trend:research (2017): Eigentümerstruktur: Erneuerbare Energien. Entwicklung der Akteursvielfalt, Rolle der Energieversorger, Ausblick bis 2020 (20-01174). Available online at http://www.trendresearch.de/studie.php?s=672, checked on 2/28/2018.

Umweltbundesamt (2017a): Energieeffizienz in Zahlen. Edited by Bundesministerium für Wirtschaft und Energie (BMWi). Available online at http://www.bmwi.de/Redaktion/DE/Publikationen/Energie/energieeffizienz-inzahlen.pdf?_blob=publicationFile\&v=10, checked on 1/4/2018.

Umweltbundesamt (2017b): Energieverbrauch privater Haushalte. Available online at https://www.umweltbundesamt.de/daten/private-haushalte-

konsum/wohnen/energieverbrauch-privater-haushalte, checked on 2/19/2018.

Umweltbundesamt (2017c): Treibhausgas-Emissionen in Deutschland. Available online at https://www.umweltbundesamt.de/daten/klima/treibhausgas-emissionen-indeutschland\#textpart-1, checked on 1/29/2018.

Unternährer, Jérémy; Moret, Stefano; Joost, Stéphane; Maréchal, François (2017): Spatial clustering for district heating integration in urban energy systems. Application to geothermal energy. In Applied Energy 190, pp. 749-763. DOI: 10.1016/j.apenergy.2016.12.136.Walberg, Dietmar; Holz, Astrid; Gniechwitz, Timo; Schulze, Thorsten (2011): Wohnungsbau in Deutschland - 2011 - Modernisierung oder Bestandsersatz. Studie zum Zustand und der Zukunftsfähigkeit des deutschen "Kleinen Wohnungsbaus". Kiel: Arbeitsgemeinschaft für Zeitgemäßes Bauen (Bauforschungsbericht, 59).

Yılmaz Balaman, Şebnem; Selim, Hasan (2016): Sustainable design of renewable energy supply chains integrated with district heating systems. A fuzzy optimization approach. In Journal of Cleaner Production 133, pp. 863-885. DOI: 10.1016/j.jclepro.2016.06.001. 


\section{A.1. Current status of the German biogas industry}

At the end of 2017, the number of biogas plants in Germany stood at around 10,500 plants. This makes Germany the country with the largest biogas plant population in Europe by far (European Biogas Association 2016), clearly over-fulfilling the National Renewable Energy Action Plan (NREAP) targets for 2015 (Pablo-Romero et al. 2017). The 10,500 plants relate to $4.3 \mathrm{GW}_{\mathrm{el}}$ and $25.7 \mathrm{TWh}_{e l}$ of capacity and generation respectively in 2015 (Engel 2015).

A period of fast growth between 2009 and 2011 saw the installation of more than 1,300 new plants per year on average. The expansion of the sector subsequently came to a halt in 2012 and the average number of newly built plants dropped to an average of below 150 per year for the period from 2014 to 2016 (German Biogas Association 2017). The main growth driver until 2012 was the German Renewable Energy Sources Act, which guaranteed generous feed-in-tariffs (FIT) for electricity produced in biogas plants. It especially promoted the use of energy crops, which is why $51 \%$ of all material input of German biogas plants consists of energy crops, of which $73 \%$ is maize silage (FNR 2017). But the public as well as the political discourse have turned against the use of energy crops (Herbes et al. 2014). Subsequently, policy makers first introduced a cap on the amount of maize silage that can be used in new plants and finally redesigned the subsidy system in a way that only allows very few new plant projects to be financially viable (Markard et al. 2016; Herbes et al. 2014). Recently, the German government introduced a tender system for electricity from biomass, but the first tender in September 2017 was perceived as unsuccessful, since the bids totalled to only about a third of the tender volume (Bundesnetzagentur 2017a). While not many new biogas plants are built at the moment, the outlook for the existing sites beyond the end of their 20 year FIT period is unclear, and without a new remuneration period, a large part of the plant population in Germany will be shut down (Lauer \& Thrän 2017).

The majority of German plants use the gas onsite to fuel combined heat and power (CHP) units, thus cogenerating heat and electricity. The electricity is fed into the electricity network to receive a feed-in tariff, and heat is used locally if at all feasible. A further around 200 plants (in 2016, around 9 TWh of gas, cf. dena 2016) upgrade the biogas into biomethane or Bio-SNG (Synthetic Natural Gas) and inject it into the public gas grid (cf. Figure 16). Particularly where a local heat sink is lacking, despite the overall utilisation efficiency of biogas valorisation. For example, a typical CHP unit can achieve $40 \%$ electrical efficiency, reaching an overall efficiency of up to $80 \%$ if all the generated heat can be used locally (Pöschl et al. 2010). In the absence of a local heat sink, biogas upgrading and feed-in can result in overall efficiencies of around $75-80 \%$, based on the utilisation of Bio-SNG as a fuel for transport, for heating and/or power generation (Niesner et al. 2013, Köppel et al. 2014). 


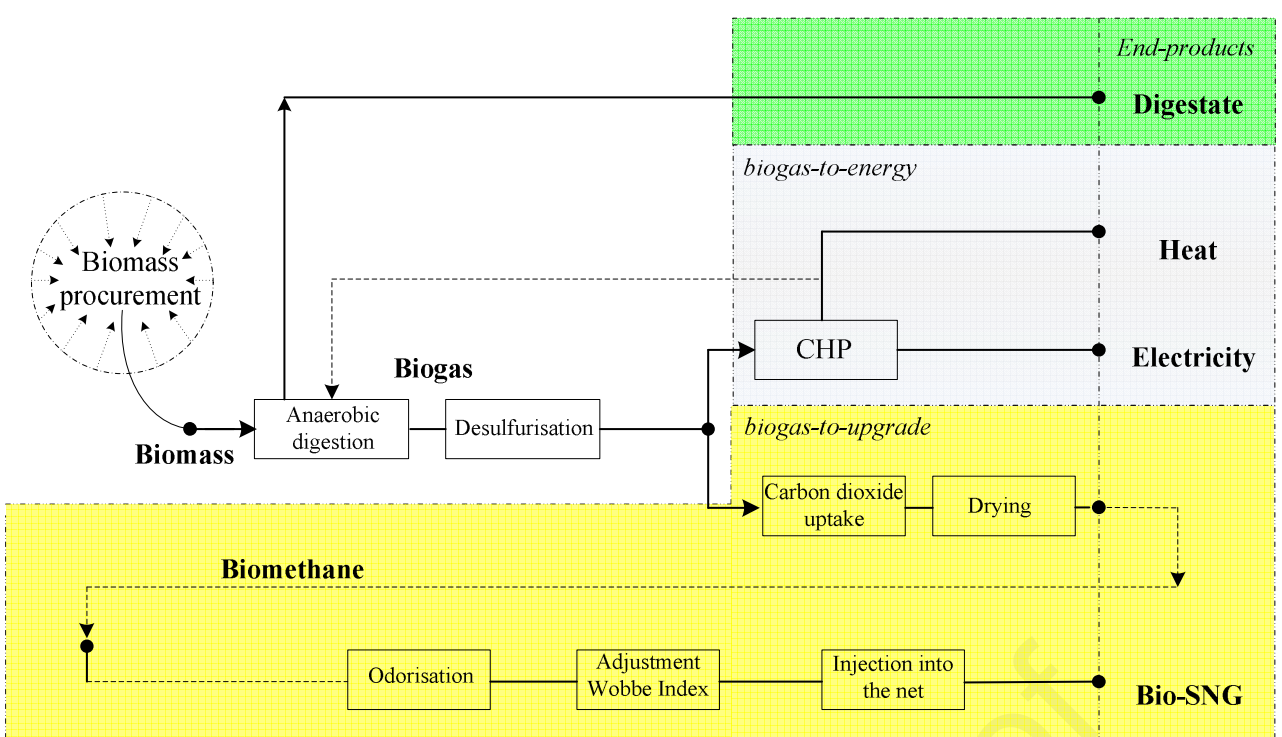

Figure 16: Schematic of biogas plant, showing key valorisation steps and pathways (Figure from Bidart (2013))

What are potential future perspectives for biogas in Germany, given the reduced financial support for electricity from biogas and the widespread reservations against biogas from energy crops? In order to compensate the reduced income from FIT or auction prices for electricity from biogas, plant operators need to open up new income streams in the near and middle future. At the moment, three such streams look promising.

The first one is offering system services to network operators, e.g. balancing energy (Bundesnetzagentur 2017b). In order to supply these services, plant operators have to invest into flexibility, i.e. gas storage and additional CHP units (Hahn et al. 2014, Hochloff/Braun 2014, Ertem et al. 2016, Lauer et al. 2017). The German Renewable Energy Sources Act incentivizes flexibilization through a premium but the prices for these services have decreased significantly reducing financial attractiveness (Bundesnetzagentur 2017b, Purkus et al. 2018). Plants with a cumulative installed capacity of $2.8 \mathrm{GWel}$ which equals about $60 \%$ of installed electrical capacity of biogas plants overall in Germany are already pursueing this strategy and benefiting from the flexibility premium under the REA (Fraunhofer IEE 2018).

A second income stream is revenues from selling heat. Many plants have unused heat and / or are selling their heat into applications with a low value added that only pay low prices, such as grain or wood drying (Herbes et al. 2018a). The application that we found most often in the survey dataset was heating of the digester $(91 \%$ of all plants under review, multiple answers possible), followed by heating of residential buildings (81\%), wood drying (47\%), heating commercial buildings (45\%) and grain drying (37\%). Innovative applications like using the heat for pre-treating the input material (e.g. Maroušek et al. 2018) or producing bio coal (e.g. Maroušek 2014) did not play any role for the biogas plants under review. This is in line with the literature as reviewed in Herbes et al. (2018a).

A third income stream is the upgrading and monetarization of digestates. The majority of digestates today is sold to agricultural businesses in the vicinity of the biogas plant without upgrading. Farmers pay very low prices and in some regions that are rich in nutrients, they even ask fees for taking on digestate. On the other hand, hobby gardeners, landscapers and other potential target groups outside the agricultural sector are looking for organic fertilizers and soil products that do not deplete finite resources e.g. in phosphorous. By upgrading their 
digestate and turning it into a marketable product, biogas plant operators can increase their value added considerably (Dahlin et al. 2015, 2016, 2017, 2018).

A fourth income stream that would replace rather than supplant income from FIT, is revenues from selling biomethane. In order to realize this stream, biogas plant operators have to invest into biogas upgrading facilities (Herbes 2017).

Another important issue is which feedstock German biogas plants will use in the future, especially given the widespread resistance against using energy crops. This will influence the long-term future of biogas in Germany. Researchers and practitioners alike are constantly looking into new types of feedstock, such as aquatic macrophytes or algae that do not compete with food production (Ertem et al. 2017, Herbes et al. 2018b). However, when looking at the total technical biomass potential in Germany in 2050, it becomes clear that the vast majority comes from energy crops (41\%) that are cultivated on arable land and wood $(38 \%)$, where the latter is not suitable for biogas plants. Household waste as a noncompeting biomass on the other hand is rather negligible with only $7 \%$ (FNR 2018). As of today, two thirds $(69 \%)$ of the technical potential of residual and waste materials, both from agriculture and from other sectors in Germany, are already used, which leaves an unused technical potential of only $31 \mathrm{~m}$ tonnes of dry matter that is either unused or where the use is unclear. If we look at material that is suitable for biogas plants, the unused potential is even much smaller with around $18 \mathrm{~m}$ tonnes of dry matter and a total energetic value of $213 \mathrm{PJ}$. $66 \%$ of that potential are straw and the rest consists mostly of various types of manure (FNR 2015). To summarize, if the biogas sector is to grow significantly, there is no way around energy crops. In other words: if biogas will be largely restricted to waste and residues in the future, a growth of this sector is impossible.

\section{A.2. Information about biogas plant survey}

Table 5: Locations of biogas plants in the sample

\begin{tabular}{lr}
\hline Federal state & $\begin{array}{c}\text { Number of biogas plants } \\
\text { in the sample (total: }\end{array}$ \\
\hline Baden-Wuerttemberg
\end{tabular}


Table 6: Size of biogas plants in the sample

\begin{tabular}{lr}
\hline Size & $\begin{array}{c}\text { Number of biogas plants } \\
\text { in the sample (total: }\end{array}$ \\
\hline Below $70 \mathrm{~kW}_{\mathrm{el}}$
\end{tabular}

\section{A.3. Heat demand calculation}

The number of buildings in the 111 areas $n_{b 111}$ and the number of buildings in the 112 areas $n_{b 112}$ is calculated in equation Eq. 13 and 14 using the total number of buildings in the square kilometre $n_{b}$ as well as the area sizes of the 111 areas $a_{111}$ and 112 areas $a_{112}$.

$$
\begin{aligned}
& n_{b 111}=\frac{\sum 0.9 \cdot a_{111}}{\sum 0.9 \cdot a_{111}+\sum 0.65 \cdot a_{112}} \cdot n_{b} \#(13) \\
& n_{b 112}=\frac{\sum 0.65 \cdot a_{112}}{\sum 0.9 \cdot a_{111}+\sum 0.65 \cdot a_{112}} \cdot n_{b} \#(14)
\end{aligned}
$$

The values 0.9 and 0.65 are the above-mentioned building densities. With the help of this procedure, the data from the census is assigned to the settlement areas. Furthermore, for comparison with data at the municipal level, it is necessary to assign settlement areas to municipalities. In QGIS, the settlement areas were also intersected with administrative boundaries of the German municipalities from Lenk et al. (2017b) for this purpose.

In Landesamt für Statistik Niedersachsen (2014), the average living space per apartment can be found for all federal states. For federal states, districts and municipalities, Statistisches Bundesamt (2015a) indicates the number of residential buildings with one apartment $\left(F_{1}\right)$, two apartments $\left(F_{2}\right)$ and three or more apartments $\left(F_{3}\right)$. In addition, the total living space is given in $\mathrm{m}^{2}\left(F_{\text {total }}\right)$. The mean living space $\left(F_{\text {mean }}\right)$ could be calculated for each federal state using Eq. 15.

$$
F_{\text {mean }}=\frac{F_{\text {total }}}{F_{1}+F_{2} \cdot 2+F_{3} \cdot x} \#(15)
$$

Variable $x$ represents the average number of apartments in a residential building with more than two apartments. The variable is adjusted iteratively for each federal state until the mean living space corresponds to the specified value of Landesamt für Statistik Niedersachsen (2014) at the federal state level. Then the value of $x$ was adopted for all municipalities in the state. In this way, the average living space $F_{\text {mean,m }}$ was determined for each German municipality $m$. For 141 of the 38,414 CLC areas, the average living space of the federal state was adopted, since there were no values for the municipalities in the housing data.

In order to calculate the living space $L S_{1}$ on CLC settlement area level, the number of apartments $n_{a}$ in the CLC area is required. The census data contains the categories "number of buildings with living space" with: 1 apartment, 2 apartments, 3-6 apartments, 7-12 
apartments and more than 13 apartments. In the last 3 categories, the average value was estimated so that the sum of the living space in the CLC areas is equal to the total living space in residential buildings in Germany (i.e. 3,670,870,000 $\mathrm{m}^{2}$ ). For this purpose, an average value of 3-6 apartments was assumed to be 5, for 7-12 apartments 9.5 and for 13 or more apartments 16 . The sum of the apartment number $(40,411,000)$ calculated in this way is taken as the number of households in the settlement areas for later calculations. Compared with the actual number of apartments on 31.12.2010 of 40,479,000, the deviation is only $-0.15 \%$ (Statistisches Bundesamt 2017a). Then the living space per CLC area $L S_{1}$ was calculated using the number of apartments $n_{a}$ and the mean living space $F_{\text {mean, } m}$ in the municipality (cf. Eq. 16).

$$
L S_{1}=F_{\text {mean }, m} \cdot n_{a} \#(16)
$$

Now the sum of the CLC's living space $L S_{\text {total } 1}$ for each municipality is compared with the measured total living space of this municipality $L S_{\text {total2 }}$ (for which data are available). If the sum of the living space $L S_{\text {total } 1}$ deviates from the total living space of the municipality $L S_{\text {total } 2}$, the new living space of each CLC area $L S_{2}$ will be adjusted accordingly to Eq. 17 .

$$
L S_{2}=L S_{1}-\left(\frac{L S_{1}}{L S_{\text {total1 }}} \cdot\left(L S_{\text {total1 }}-L S_{\text {total } 2}\right)\right) \#(17)
$$

As described above, percentages for building age are also given in the census. With the help of these parameters and specific heat demand per year, square meter and building type, the total specific heat demand per settlement area can be determined. For this purpose, the consumption values for single-family houses, two-family houses and multi-family houses are taken from Walberg et al. (2011). The calculation of consumption values in Walberg et al. (2011) also takes into account the modernisation rate for each age group. The building age classes from the census and in Walberg et al. (2011) are not completely identical, as Table 7 shows. The data has therefore been assigned in such a way that a minimal error occurs. The assignment was made according to the colours in Table $7^{5}$.

\footnotetext{
${ }^{5}$ Please refer to the online version of the article for the colours in this table and all figures.
} 
Table 7: Comparison of the building age classes from Statistisches Bundesamt (2015b) and from Walberg et al. (2011) as well as the allocation of the classes by colour.

\begin{tabular}{ll}
\hline Statistisches Bundesamt (2015b) & Walberg et al. (2011) \\
\hline Before 1919 & Before 1918 \\
$1919-1948$ & $1918-1948$ \\
& $1949-1957$ \\
$1949-1978$ & $1958-1968$ \\
& $1969-1978$ \\
$1979-1986$ & $1979-1987$ \\
$1987-1990$ & $1988-1993$ \\
$1991-1995$ & $1994-2001$ \\
$1996-2000$ & \\
$2001-2004$ & $2002-2008$ \\
$2005-2008$ & \\
2009 and later &
\end{tabular}

The census data does not reveal the age profiles of different building types in a settlement. Therefore, a mean heat demand must be calculated for the different building types. The building stock model from McKenna et al. (2013) was used to determine how the singlefamily houses/two-family houses (SFHs) and multi-family houses (MFHs) are distributed among the building age classes. This was differentiated according to new and old federal states. With the help of the specific heat demand per age group and building type from Walberg et al. (2011), the total heat demand for old and new federal states can be determined for SFHs and MFHs. These total heat demands divided by the number of SFHs/MFHs gives the mean specific heat demand per SFHs or MFHs in a settlement area.

In order to calculate the total heat demand in a settlement area (SA), the share of SFHs or MFHs in the settlement must be known. For this purpose, the mean living space (differentiated by age group, building type and federal state from the building stock model) was multiplied by the number of apartments in SFHs or MFHs in the settlement. In the case of MFHs, the number of apartments $x$ from Eq. 15 was used to determine the number of apartments. The shares of SFHs in the living space were then multiplied by the specific heat demand of the SFHs in the settlement area (MFHs analogously). The two mean specific heat demands are then added together to form the mean specific heat demand $h d_{\text {mean }}$ per settlement area. Now the total heat demand per settlement area $H D_{S A_{\text {total }}}$ can be calculated according to Eq. 18.

$$
H D_{S A_{\text {total }}}=h d_{\text {mean }} \cdot L S_{2} \#(18)
$$

\section{A.4. Determination of specific heat distribution costs}

An important parameter to determine the specific heat distribution cost is the plot ratio $e$. The plot ratio is a city planning parameter that captures the building density within an area. Plot ratio values are used to categorize typical city districts: $(A)$ inner city areas $(e=0.5-2.0),(B)$ 
outer city areas $(e=0.3-0.5)$ and $(C)$ sparse areas $(e=0-0.3)$. Those parameter ranges are based on Statens Planverk (1985). The plot ratio is calculated with the population density $P D_{S A}$ and the total building space $B S A_{S A}$ of the settlement area divided by the total population $P$ of the settlement. By dividing the calculated residential area per settlement area by the residential area per person of the municipality from Statistische Ämter des Bundes und der Länder (2011), the number of inhabitants per settlement area can be estimated. All in all, Germany will then have a population of $81.711,000$, close to the actual population of 2010 (81.750,000, Statistisches Bundesamt 2017b). By dividing the number of inhabitants by the settlement area, the population density can be determined and in the following step the plot ratio e (Eq. 19, cf. Persson \& Werner 2011).

$$
e=P D_{S A} \cdot B S A_{S A} / P \#(19)
$$

The effective width $w$ is a parameter that describes the relationship between a land area and the length of district heat pipelines within this land area. It can also be seen as a correction factor to avoid the overestimation of distribution costs and is based on the plot ratio $e$ (Persson, Werner 2011). The effective width is calculated by using Eq. 20.

$$
w=61.8 \cdot e^{-0.15} \#(20)
$$

In order to calculate the investment for heat distribution, the linear heat density $L H D_{S A}$ is necessary. The linear heat density is calculated in Eq. 21 based on the effective width, the plot ratio and the specific heat demand.

$$
L H D_{S A}=e \cdot w \cdot \frac{H D_{S A}}{B S A_{S A}} \#(21)
$$

Subsequently the average diameter of the $\mathrm{DH}$ grid $d_{S A}$ is calculated as this is one of the major cost influencing factors (cf. Eq. 22). The determination of the diameter depends on the linear heat density.

$$
d_{S A}=0.0486 \cdot \ln \left(L H D_{S A}\right)+0.007 \#
$$

Finally, the determined values are used to calculate the specific heat distribution costs $H D C_{S A}$ using Eq. 23. These costs represent the investment for distributing $1 \mathrm{GJ}$ of heat inside a settlement area. The construction cost parameters $C 1$ and $C 2$ vary depending on the plot ratio e. $C 1$ is a base cost that solely depends on the length of the heat pipe, whereas $C 2$ depends on the pipe diameter $d_{S A}$. Three district types are considered in this study and for each type there are different cost parameters applied. The higher the plot ratio $e$, the higher are $C 1$ and $C 2$. In Table 8 the values for the construction cost parameters $C 1$ and $C 2$ can be found for the according district plot ratio and the district type. Furthermore, an annuity factor af of 0.08 is integrated in the calculation.

$$
H D C_{S A}=\frac{a f \cdot\left(C 1+C 2 \cdot d_{S A}\right)}{L H D_{S A}} \#(23)
$$

Table 8: Cost parameter values and district type according to plot ratio range (Persson \& Werner 2011)

\begin{tabular}{llll}
\hline Plot ratio $(\mathbf{e})$ & $\mathbf{C 1}[\boldsymbol{\epsilon} / \mathbf{m}]$ & $\mathbf{C 2}\left[\mathbf{\epsilon} / \mathbf{m}^{2}\right]$ & District Type \\
\hline $0.5 \leq \mathrm{e}$ & 286 & 2022 & Inner city $\operatorname{area}(\mathrm{A})$ \\
$0.3 \leq \mathrm{e}<0.5$ & 214 & 1725 & Outer city area $(\mathrm{B})$ \\
$0 \leq \mathrm{e}<0.3$ & 151 & 1378 & Park area $(\mathrm{C})$ \\
\hline
\end{tabular}

